Article

\title{
Evaluation of a New Statistical Method-TIN-Copula-for the Bias Correction of Climate Models' Extreme Parameters
}

\author{
Georgia Lazoglou ${ }^{1,2}{ }^{2} * \mathbb{D}$, Christina Angnostopoulou ${ }^{1} \oplus$, Konstantia Tolika ${ }^{1}$ and \\ Gräler Benedikt ${ }^{3}$ \\ 1 Department of Meteorology Climatology, School of Geology Aristotle, University of Thessaloniki, \\ GR54124 Thessaloniki, Greece; chanag@geo.auth.gr (C.A.); diatol@geo.auth.gr (K.T.) \\ 2 Climate and Atmoshere Research Center (CARE-C), The Cyprus Institute, 20 Konstantinou Kavafi Street, \\ 2121 Aglantzia, Nicosia, Cyprus \\ $352^{\circ}$ North Initiative for Geospatial Open Source Software GmbH, Martin-Luther-King-Weg 24, \\ 48155 Muenster, Germany; b.graeler@52north.org \\ * Correspondence: glazoglou@geo.auth.gr or glazoglou@gmail.com
}

Received: 21 January 2020; Accepted: 27 February 2020; Published: 29 February 2020

check for updates

\begin{abstract}
During the last decades, global and regional climate models have been widely used for the estimation of future climate conditions. Unfortunately, the models' estimated values present important biases relative to the observed values, especially when the estimations refer to extremes. Consequently, several researchers have studied several statistical methods that are able to minimize the biases between climate models and observed values. The present study evaluates a new statistical method for bias correction: The triangular irregular network (TIN)-copula method. This method is a combination of the triangular irregular networks and the copula theory. In the present research, the new method is applied to ten Mediterranean stations and its results are compared with the bias-corrected values of three other widely used methods: The delta, the scaling, and the empirical quantile mapping methods. The analysis was made for maximum mean temperature (TMX) and minimum mean temperature (TMN) as well as for extreme precipitation (R99). According to the results, the TIN-copula method is able to correct extreme temperature and precipitation values, estimated by regional climate models, with high accuracy. Additionally, it is proven that the TIN-copula method is a useful tool for bias correction as it presents several advantages compared with the other methods, and it is recommended for future works.
\end{abstract}

Keywords: TIN-copula; triangular irregular networks; copula; bias correction; Mediterranean; extremes

\section{Introduction}

General circulation models (GCMs) and regional climate models (RCMs) constitute widely used tools for analyzing the Earth's climate and for estimating future climate conditions [1]. Additionally, both the increasing frequency of extreme climate episodes as well as their severe impacts in several fields (society, economy, agriculture) have made the use of climate models necessary. However, the simulated outputs from circulation climate models present systematic biases compared with the observed values [2-4], especially for extremes. Consequently, according to Sharma et al. [5] and Hansen et al. [6], a pre-process of models' outputs is required before their use. The pre-process is achieved with the use of statistical methods, namely bias correction methods. The purpose of these methods is to minimize the biases between climate models' data and observations. Bias correction methods are preferred by scientists as they are easily applicable, flexible for correcting the simulation 
of the climate model, and able to consider the variability of the data sets [7]. The effectiveness of bias correction methods has been investigated by several scientists. Lafon et al. [8] tested four widely used bias correction methods for their ability to correct the precipitation biases in the region of Great Britain, while similar research was accomplished for North America, by Chen et al. [9]. Furthermore, rigorous studies have been made for extremes' bias correction on account of their catastrophic impacts $[10,11]$.

Some of the most used bias correction methods are the "delta", "scaling" and "empirical quantile mapping" methods.

According to Navarro-Racines [12], the delta method is a simple form of the "change factor" approach for the bias correction of climate models. The main concept of this method is the transferring of the mean change signal between the observed and model data from a historical time period to the model's data [13]. In particular, two time series (historical and present) of the studied climate model are used, in order to calculate their differences—the so-called "climate anomalies" [14]. Following that, the estimated data set (climate anomalies) is added to the observed values, resulting in the bias-corrected values of the climate model. Additionally, despite the fact that the delta method is proposed for any kind of data, it should not be used for bounded variables-such as the under zero wind speed values-because it is possible to obtain values that are out of the variable range [15]. The simplicity of this method makes it preferable for several researchers who have used it (or its similar form) for the bias correction of climate data $[13,16,17]$.

The scaling method is considered to be the simplest method for bias correction [18], resulting in its widespread adoption $[18,19]$. In this method, initially, the differences between the simulated and observed values are estimated for the default-historical time period calculating a scaling factor. Following this, the estimated factor is used for the bias correction of the climate models' values [15]. More specifically, if the bias-corrected parameter is the temperature, then the additive version of the factor is preferred, as it is more appropriate for unbounded variables. However, for lower bounded parameters (precipitation), the multiplicative version of the estimated factor should be used, as it preserves the frequency [15].

The empirical quantile mapping (EQM) is an extended bias correction method which is focused on the entire distribution [20]. The empirical transformations, proposed by Panofsky and Brier [21], have been used for the formation of a bias correction method based on quantiles (EQM). Empirical Quantile Mapping calibrates the simulated values by the observed ones, using their cumulative distribution functions (CDF).

Another method which has recently been introduced as a bias correction method is the copula. The copula has mainly been used for bias correction of hydrological and climatological parameters. The main advantage of this method is its ability to model the dependence of two or more variables which have different marginal distributions [22]. One of the most recent studies using the copula method for the bias correction of climate models' precipitation values was made by Lazoglou et al. [23]. In this study, the precipitation values in the river basin of Nestos (Greece) were improved significantly after bias correction, and consequently, the hydrological discharges in this area were predicted with much higher accuracy. A similar hydrological study, although not for extremes, was carried out for the region of Germany, where the precipitation values of the Weather Research and Forecasting (WRF) model were bias-corrected using copula [24]. For the same country, Piani et al. [25] propose the copula method as a useful tool for temperature and precipitation bias correction.

Several bias correction techniques have been developed by various scientists in several fields (climatology, meteorology, hydrology), some of them with highly satisfactorily results and some with lower. For example, Piani et al. [26] proposed a solely intensity-based bias correction method for precipitation parameter, which assumes that the distributions of both simulated and observed data sets can be fitted in gamma distribution. In 2012, Watanabe et al. [27] combined the changes of standard deviation, mean values, and the variation coefficient $(\mathrm{CV})$ for temperature with the changes of mean precipitation, and produced a new bias correction method. Additionally, they compared their method with other widely used methods, showing that the results were satisfactory. In summary, there is a 
need for improving biases between the climate models values and the observed one's in the creation of new bias correction techniques with improved results [28,29].

Considering the extended use of bias correction methodologies, this study aims to compare the results of three widely used methods with the results of a new statistical method for bias correction, the triangular irregular network (TIN)-copula method. Hence, the main objective of this study is to evaluate the TIN-copula method for its efficiency to correct the biases between climate models' estimations and observations for the parameters of extreme temperature and precipitation.

\section{Data}

For analyzing extreme climate events, data with high reliability are required. Thus, the primary source of the data sets used in the present study was produced by the European Climate Assessment \& Dataset project (ECA\&D) [30]. Particularly, daily data sets of temperature and precipitation for 26 stations located across the Mediterranean region (from Spain to Greece) were used (Figure 1). The data cover a 20-year period from 1981 to 2000 . Additionally, the present research employs daily values of temperature and precipitation from the Regional Climate Model RegCM4 [31], provided under the framework of Med-Cordex and Coupled Models Intercomparison Project Phase 5 (CMIP5) programs (www.medcordex.eu). The driving forces of the used model (RegCM4) were provided by the general circulation model (GCM) ECHAM5/MPI which uses the 8.5 Representative Concentration Pathway (RCP), the most extreme scenario (RegCM4-MPI). The models' data cover the same time period with ECA\&D data as well as the same region (Mediterranean).

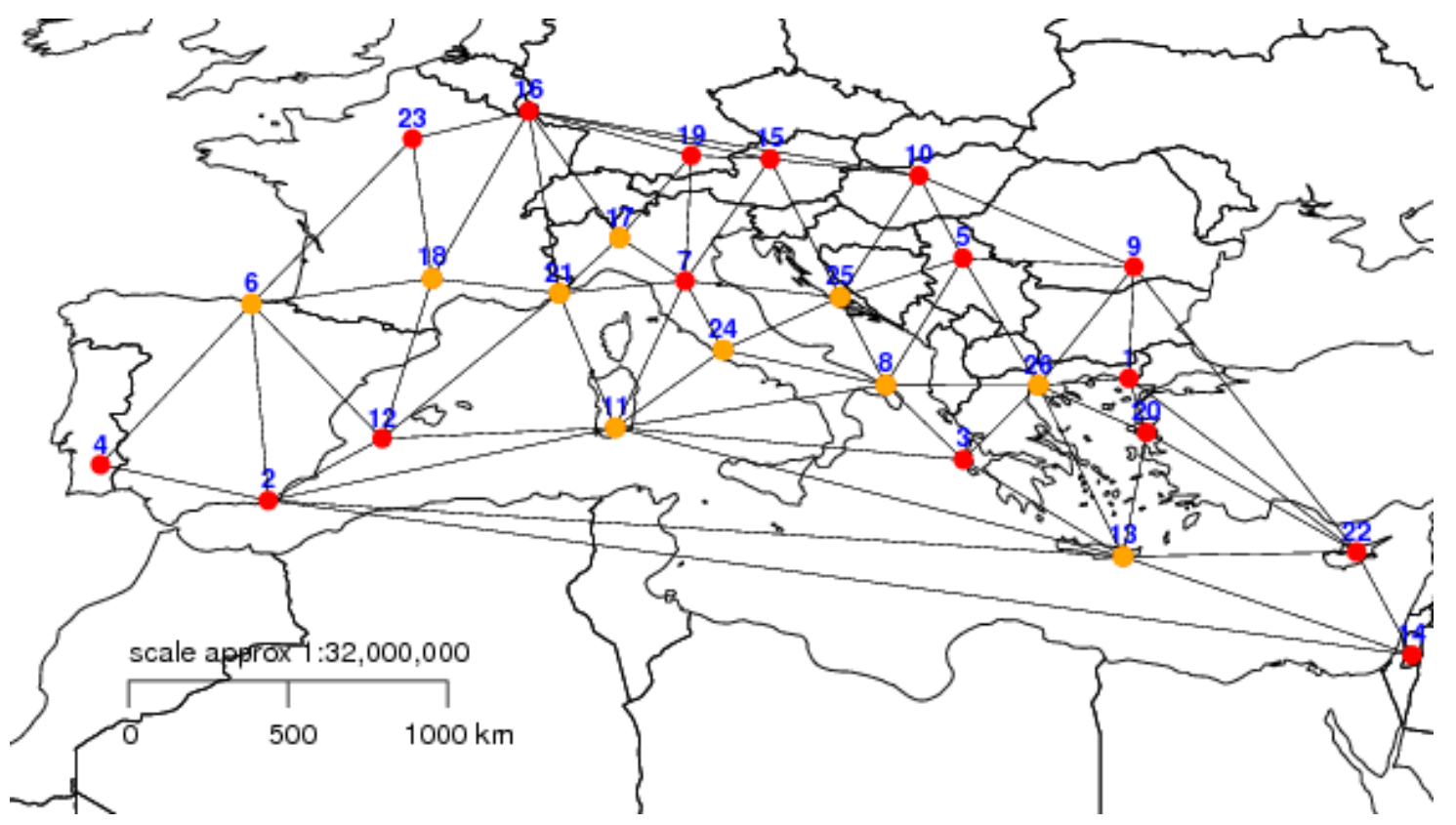

Figure 1. Location of the 26 used stations (red and orange points) and the formatted triangular irregular network (TIN). The orange points show the ten stations which are used for evaluation. 1: Alexandroupoli, 2: Almeria, 3: Argostoli, 4: Beja, 5: Belgrade, 6: Bilbao, 7: Bologna, 8: Brindisi, 9: Bucuresti, 10: Budapest, 11: Cagliari, 12: Ibiza, 13: Ierapetra, 14: Jerusalem, 15: Kremsmuenster, 16: Luxembourg, 17: Milan, 18: Millau, 19: Muenchen, 20: Mytilene, 21: Nice, 22: Nicosia, 23: Orly, 24: Roma, 25: Split, 26: Thessaloniki.

\section{Methodology}

The present study proposes and evaluates a new statistical method for bias correction, namely the TIN-copula method. The evaluation of the TIN-copula method is based on its ability to correct the biases between climate models' estimations for extreme climate values and the corresponding 
observations. The proposed method is a combination of the triangular irregular networks (TIN) and the copula theory. This method was first developed and presented by Lazoglou et al. [32], who used TIN-copula method for the estimation of extreme temperatures in Greece using only observational data.

For the application of the TIN-copula method, the appropriate database should be created. The available daily values are used for estimating the monthly mean temperature and monthly precipitation totals. Extreme climate parameters are defined in terms of percentile thresholds. More specifically, extreme temperatures are the 95th percentile of the daily mean temperature per month (TMX) and the 5 th percentile of the daily mean temperature per month (TMN). Extreme precipitation is defined as the daily precipitation amount at the 99th percentile of all rainy days (precipitation $>0.1 \mathrm{~mm}$ ) (R99)

The main steps of the TIN methodology are presented in Figure 2, while Figure 3 is used for its explanation. Firstly, using the stations' data (red points, Figure 3) several triangles are produced (Figure 3, blue triangles) based on the triangular irregular networks (TIN) (Step 1, Figure 2). Triangular irregular networks were first conceptualized by Peucket [33] and defined by Peucket et al. [34,35]. According to triangular irregular networks, a specific region can be covered by non-overlapping triangles which are formatted based on the Delaunay triangulation [36]. The vertices of the formatted triangles are the location of the known points—-known as stations.

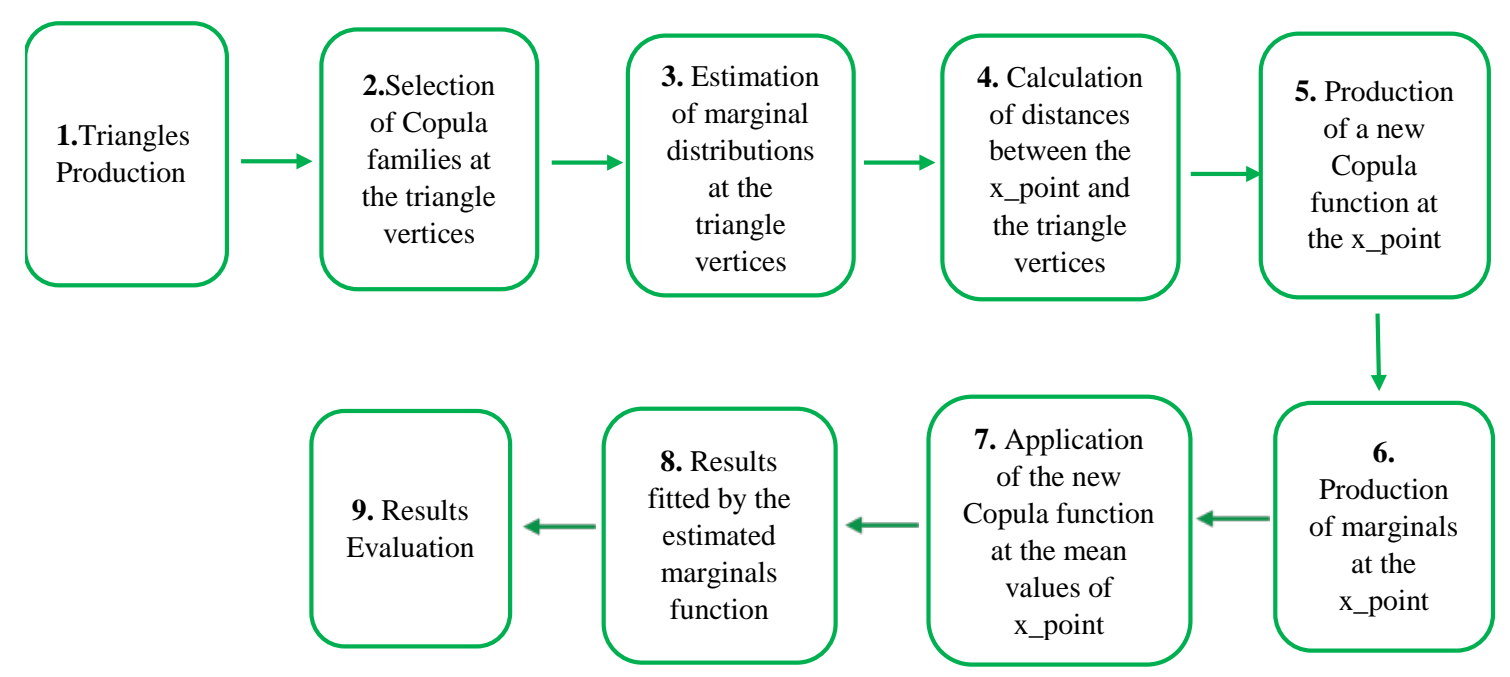

Figure 2. Methodology flowchart.
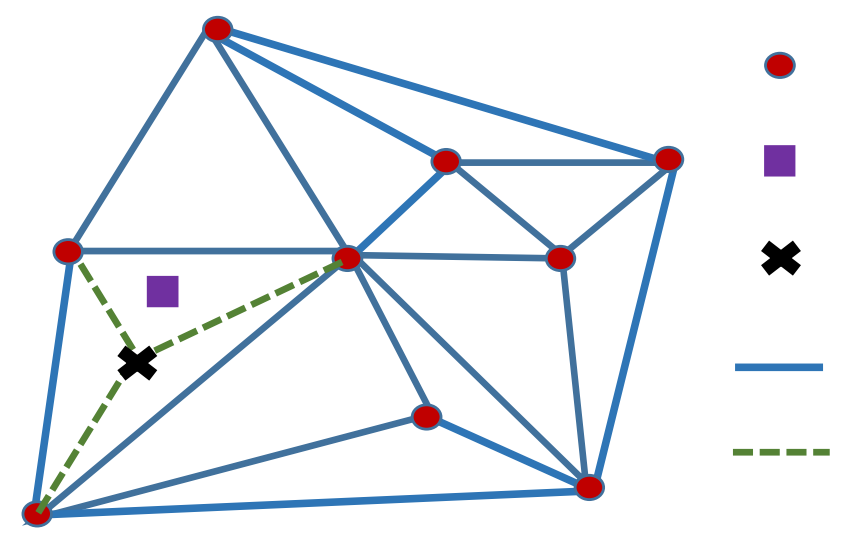

\section{Known points (stations)}
Excluded station - used for evaluation

The closest climate models' grid

point to the excluded station

(x_point)

Triangle edges

Distance between known points
and $x \_$point

Figure 3. Methodology scheme.

Following the formation of the triangles, a copula family is selected for every known point/station (Figure 3, red points) (Step 2, Figure 2). More specifically, in the present research, 12 copula families were tested at the vertex of each triangle in order to select the one which best described the dependence between the mean and extreme data sets. The analysis was implemented separately for the three 
studied climate parameters (TMX, TMN, and R99). The tested copula families (Gumbel, Frank, Clayton, Normal, Joe, Student-t, BB1, BB6, BB7, BB8, Tawn type 1 and 2) come from both the Archimedean and Elliptical categories and the final selection is achieved with the AIC [37] and BIC criteria [38]. Except for the copula families, the marginal distributions of extremes at every known point (Figure 3, red points) are also calculated (Step 3, Figure 2). Particularly, the gamma, normal, log-normal, generalized extreme value distribution (GEV), and Pareto distributions are tested and the selection of the most appropriate distribution is made according to the AIC and BIC criteria. The final element, which is calculated before the application of the proposed method, is the distance between the x_point (Figure 3, black point) and the triangle's vertices (Figure 3, red points) where the x_point belongs to (Figure 3, green lines) (Step 4, Figure 2).

Using the selected copula families and marginal distributions at the studied triangle (where the x_points belongs), as well as the distance between the x_point and the triangle vertices, the application of the TIN-copula method can be implemented. Specifically, a new mathematical function is formatted at the x_point, describing the dependence between mean and extreme climate parameters. For the formation of the new copula function at the $\mathrm{x} \_$point, the selected copula families at the triangle vertices, as well as their respective distances are combined (Step 5, Figure 2). The copula family of the known point which has the smallest distance from the x_point has the greatest weight in the final function, while the most remote one has the lowest weight. In the same way, a formation of a function that combines the marginal distributions of the triangle vertices is also performed (Step 6, Figure 2).

Following the formation of the new copula function at the $\mathrm{x} \_$point, the mean values of the studied climate variable at x_point—which are the climate models' values—are used as inputs in the copula function and a new data set is estimated (Step 7, Figure 2). The calculated data set is fitted by the respective marginal function, which is calculated for the x_point, and the bias-corrected extremes are estimated (Step 8, Figure 2). Finally, the bias-corrected extremes from the TIN-copula method are compared with the extreme data sets of the station which is the closest to the x_point (Figure 3, purplepoint) and which is excluded from the triangles' formation (Step 9, Figure 2).

Except for the TIN-copula method, the x_point extremes are bias-corrected with three other widely used methods: The delta method, the scaling method and the empirical quantile mapping method. Figure 4 presents the concept of the three used methods.

Primarily, the "delta" method is used, for which the biases between the simulated-model data during two time periods (historical-1st sub-period, and future-2nd sub-period) are calculated. Furthermore, the estimated values are transferred to the historical period observed values (1st sub-period), resulting in the bias-corrected data for the future-studied period (Figure 4).

In the "scaling" method, the biases between the observed values and the simulated-model values of the historical period (1st sub-period) are estimated, leading to the calculation of the scaling factor. This factor is then transferred to the simulated-model values for a future-studied period (2nd sub-period) (Figure 4). The way that this factor is used depends on the studied parameter. For example, this factor is added to the studied time-series for the temperature. However, if the bias correction is about precipitation or other lower bounded parameters, then the production is proposed [15].

The "change factor" bias correction methods have satisfactory results for non-stochastic parameters, such as temperature. However, for the bias correction of parameters with more stochastic characteristics (e.g., precipitation) a different approach should be preferred (EQM) [12]. The "empirical quantile mapping" method focuses on the whole distribution of the studied parameter [20], as it calibrates the simulated-model values based on the observed ones using their cumulative distribution functions (CDFs). More specifically, a transferred function is fitted using the observed and the simulated-model values for a historical period (1st sub-period). Following that, the fitted function is applied to the simulated-model values of a future-tested period (2nd sub-period) for their correction (Figure 4). Despite the fact that the EQM is a complex bias correction method, it presents satisfactory results, even for stochastic variables such as solar radiation [39]. Additionally, the EQM method counts the biases 
for all statistical moments without assuming that the biases of the historical periods will be constant for future periods [11].

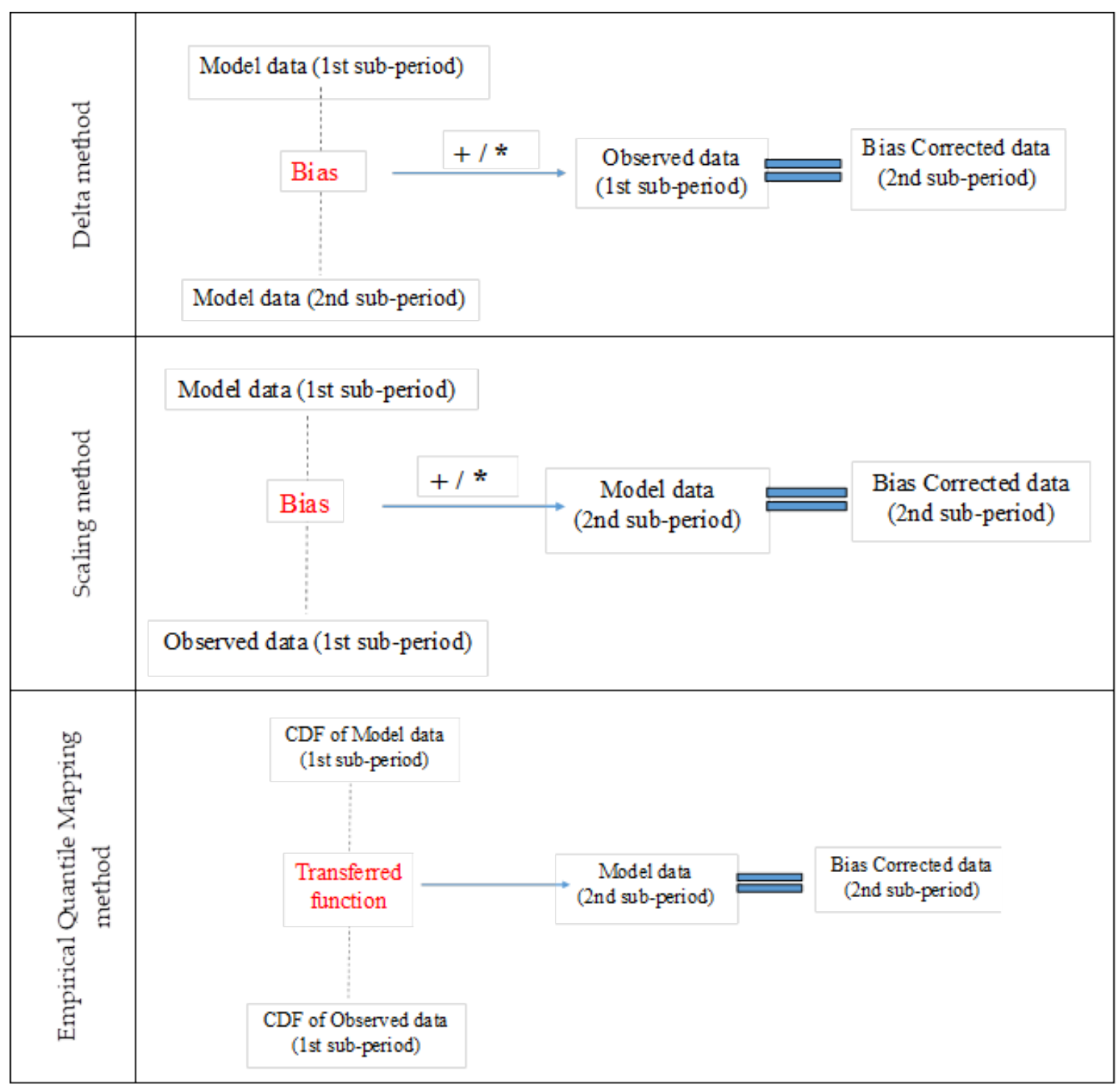

Figure 4. The use concept of delta, scaling, and empirical quantile mapping (EQM) methods.

The results of the TIN-copula, delta, scaling, and EQM methods are compared with the climate models' monthly extremes (RegCM4-MPI), as well as with the closest station's extremes. According to Figures 4-6, it is perceived that two sub-periods are needed in order to use these three bias correction methods (1st and 2nd sub-periods). Consequently, in the present study, the available data set was separated into two sub-periods. The first one is considered as the trial period (1981-1990) while the second one is the period of the validation period (1991-2000). 


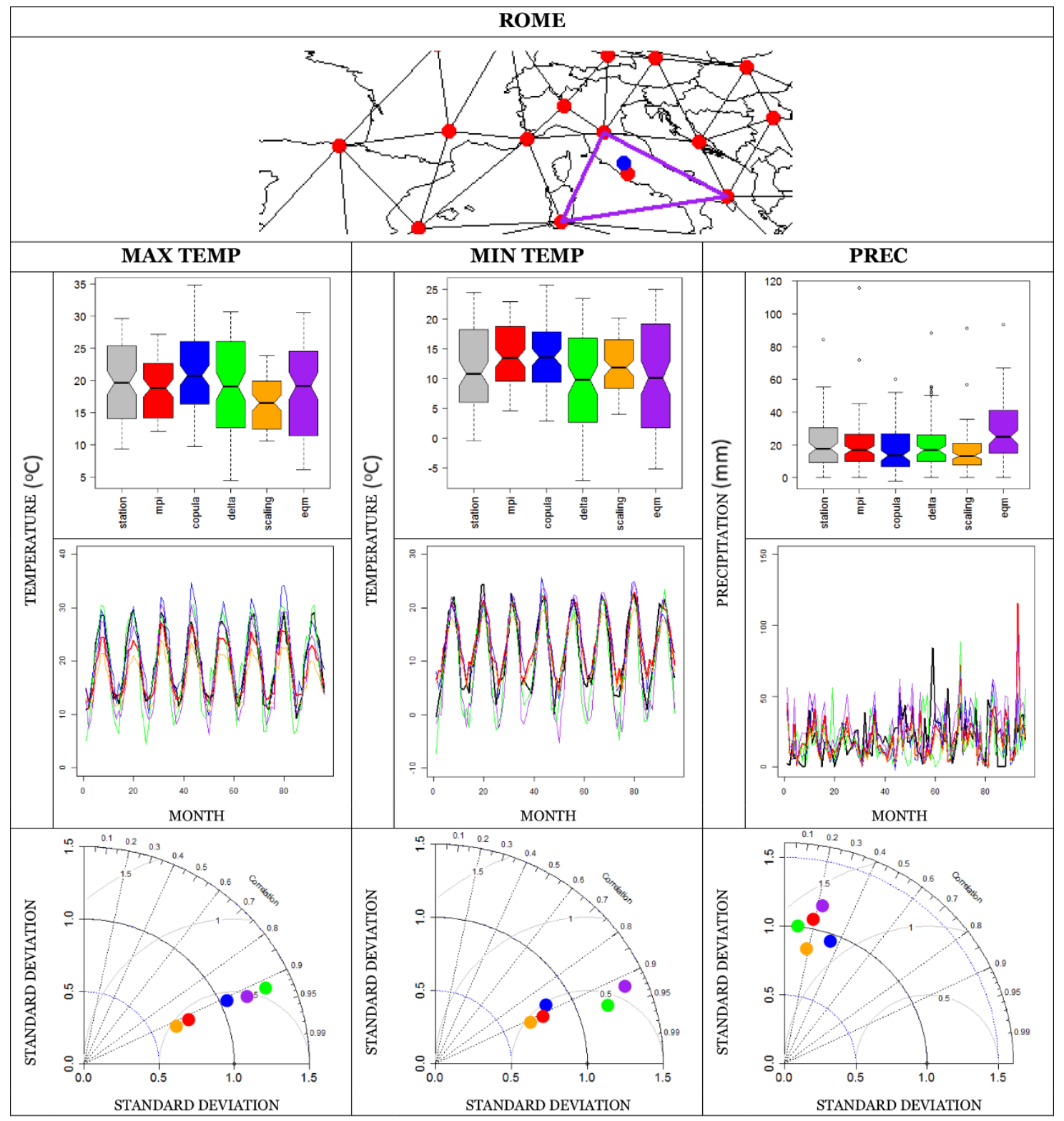

Figure 5. The map of the figure shows the location of the reference station (red point), the closest RegCM4-MPI grid (blue point), and the triangle which includes these points (purple triangle). The boxplots, line plots, and Taylor diagrams present a comparison between the observed, the models and the bias-corrected values (with the four methods) for the three studied parameters (TMX, TMN, R99). In diagrams, there is a correspondence between the colors and the presented data sets: GREY = Observations Red = RegCM4-MPI, Blue = TIN-copula, Green = Delta, Orange = Scaling, PURPLE $=$ EQM. 


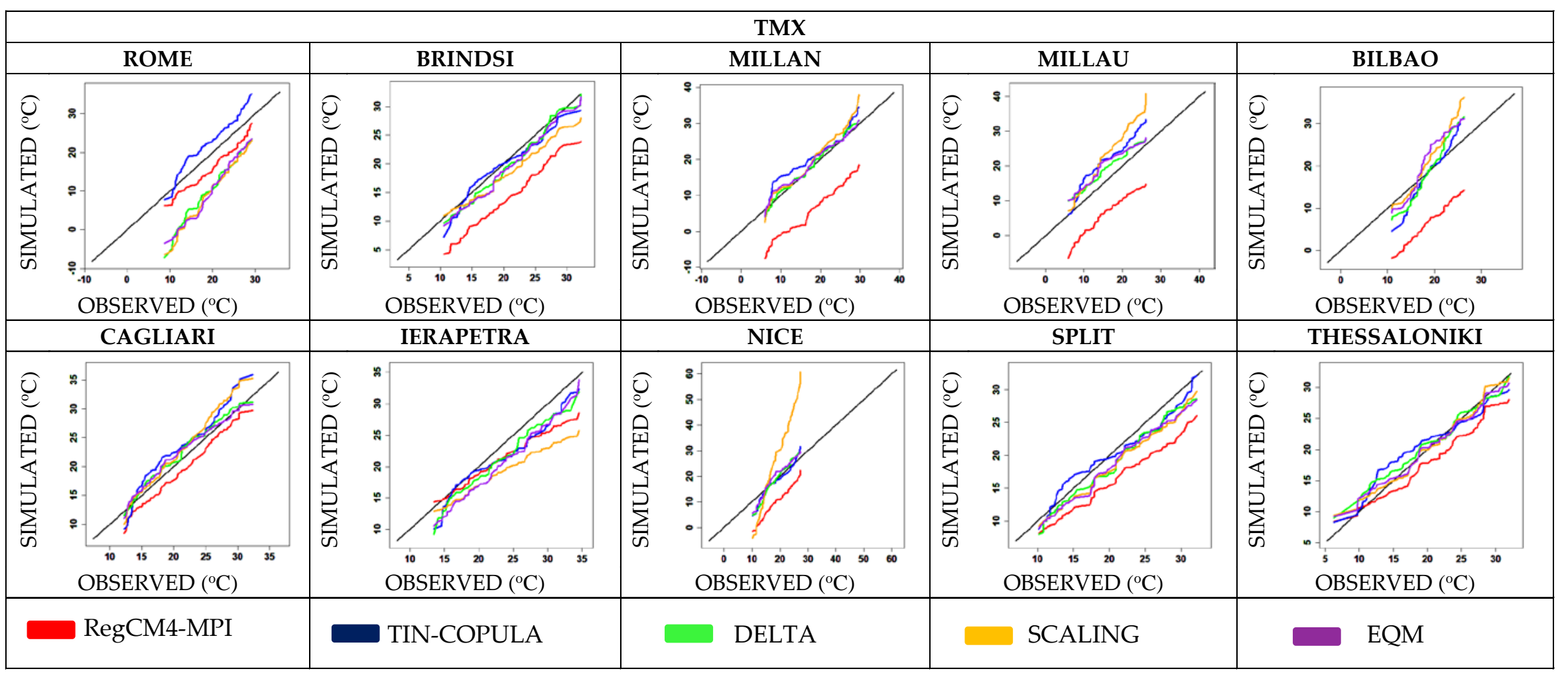

Figure 6. QQ plots of the evaluated bias correction methods for the 10 selected stations and for maximum mean temperatures (TMX). 


\section{Results}

\subsection{Selected Stations and Triangles Formation}

For precipitation and temperature, data from 26 stations (Figure 1) are used. The 26 stations (Figure 1, red and orange points) are used for the formation of the triangular irregular network (TIN), while the ten stations (Figure 1, orange points) are used both for triangle formation and for the TIN-copula method's evaluation. Specifically, the evaluation of the TIN-copula method is achieved by analyzing ten case studies, i.e., ten stations (Figure 1, orange points). In every case study, one of the ten evaluated stations are excluded from the formation of the triangles and are used for evaluation-application of the TIN-copula, delta, scaling, and empirical quantile mapping methods. The selection of the ten stations is made according to two criteria. Firstly, the selected stations must be included by a triangle and secondly the stations should cover the study area uniformly. If two or more stations satisfy both of the two requirements the final selection is made randomly.

Using the existing stations, and based on the triangular irregular network (TIN), several non-overlapping triangles have been formatted in the studied area (Figure 1, triangles). The triangles were made separately for each case study as the evaluated station is excluded in each case.

\subsection{Evaluation of the TIN-Copula Method}

\subsubsection{Evaluation with Boxplots-Line Plots and Taylor Graphs}

Figures 5 and A1, Figures A2-A9 (Appendix A) present the evaluation of the four bias correction methods using boxplots, line plots, and Taylor diagrams for the three studied extreme climate parameters (TMX, TMN, and R99). Additionally, the map, included in these figures, presents the location of the x_point-models' grid (blue bullet), the location of the reference station (red bullet), and the triangle which includes these points (purple triangle). The four methods are presented with the same colors in all graphs: TIN-copula method (blue), delta method (green), scaling method (orange) empirical quantile mapping method (EQM) (orange), and the RegCM4-MPI values (red). Finally, it should be mentioned that the grey color in the boxplots shows the extreme values of the reference station.

For the majority of the reference stations, the values of the RegCM4-MPI model present significant differences both from the observed temperature and the precipitation extremes. According to the boxplots, line plots, and Taylor diagrams, the RegCM4-MPI model underestimates the maximum mean temperatures in all stations under study. A similar behavior is observed in the six of the ten stations (Bilbao, Cagliari, Millan, Nice, Split, Thessaloniki) for the TMN, while the TMN is overestimated for the stations (Brindisi, Millau, Rome). In three stations, the model overestimates the stations' values (Brindisi, Millau, Rome). Finally, the precipitation parameter, (R99) is overestimated by the RegCM4-MPI model in six stations (Bilbao, Cagliari, Milan, Millau, Nice, Thessaloniki), in one station, the RegCM4-MPI model underestimates the observed precipitation extremes (Brindisi), while for the other three stations the values are very similar.

\section{Temperature}

According to Figure 5 and Appendix A Figures A1-A9, the TIN-copula method presents satisfactory results for the parameter of maximum mean temperature for most of the reference stations. Particularly, for half of the stations, the TIN-copula results are similar to the observed ones, especially for the values between the first and third quartile. However, there is an overestimation (underestimation) for extreme high (low) maximum mean temperature in these stations (Rome, Nice, Bilbao, Brindisi, Cagliari, Bilbao). Additionally, in most of the stations, the TIN-copula method's results present similarities with delta and EQM methods. However, in two stations (Bilbao, Nice), delta and EQM methods have a larger range from the observed values compared with the TIN-copula results, while in the two other stations (Brindisi, Rome), the same methods underestimate the observed values. In Ierapetra, Millan, 
and Thessaloniki, the TIN-copula method results are very similar to the results of the delta and EQM methods and approach satisfactorily the observed ones. Conversely, there are two stations where both the TIN-copula method overestimates the stations' extremes (Millau) or present lower ranges (Split) than the observed. It should be mentioned that at the majority of the stations, the scaling is the worst method, with the poorest results, as it presents expanded range (Thessaloniki and Millau, Milan), underestimates the observed values (Ierapetra) and overestimates them (Cagliari), importantly scientifically. These results can also be seen in the line plots as well as in the Taylor diagrams. According to the line plots of all stations, both the TIN-copula method and the other methods present similar variability with the observed values. Consequently, the correlation between the tested data sets is higher than 0.9 at almost all stations and for all methods, including the new TIN-copula. Finally, in the stations where the bias correction methods have a large range in the boxplots are the same stations presenting the highest values of standard deviation in the Taylor graphs (e.g., Ierapetra, Milan, Millau, Thessaloniki).

Regarding the minimum mean temperature (TMN) (Figure 5), the TIN-copula method presents similarities with the other three bias correction methods. In some cases, its results approach the observed results better than the other methods (Ierapetra, Milan, Thessaloniki), as the bias-corrected values with the TIN-copula method are closer to the observed ones. At the majority of stations, all methods estimate almost equal values (Bilbao, Brindisi, Nice, Split), while in some cases, the results of the studied methods (or one of them) show important differences among them (Cagliari, Millau, Rome). In six stations, almost all methods demonstrate similar results. In three stations, a slight overestimation of the station values is observed (Bilbao, Brindisi, Milan), while in the other three the values are slightly underestimated (Cagliari, Millau, Rome). It should be mentioned that in most of the studied stations (Bilbao, Brindisi, Cagliari, Ierapetra, Nice, Rome, Split), some of the evaluated methods, and especially the TIN-copula method, present extremely high or low (or both) minimum temperatures, which differ importantly from the observed ones. These results can also be seen in both the line plots and Taylor graphs. Particularly, according to the line plots, all the bias-corrected data sets present similar variability with the stations' extremes. This is also observed in the correlation values of the Taylor graphs, which are higher than 0.9 in all stations. The standard deviation values (Taylor graphs) represent the large range of the data sets, which can also be observed in the respective boxplots. The highest levels of standard deviation are observed at the stations of Milan, Millau, and Thessaloniki by the scaling method, in Rome and Ierapetra by the delta and the EQM methods, and in Bilbao by the TIN-copula method. In the rest of the stations, all the evaluated methods present similar values.

\section{Precipitation}

The results of the precipitation parameter (R99) (Figure 5) present crucial differences from the temperature parameter (both TMX and TMN). In general, the TIN-copula method approaches the mean values of extreme precipitation (R99) at almost half of the studied stations (Brindisi, Ierapetra, Nice, Rome, Split). In many of them, the TIN-copula method has similarities with some of the other bias-corrected methods. For example, in Brindisi, both the TIN-copula and the EQM methods give satisfactory results, while in Nice, Rome, and Split, all the methods approach the stations' extremes, except for the EQM method. Apart from the stations where the proposed method approaches extremes, there are cases where both the TIN-copula method and the other methods diverge from the observed values. In some stations, this deviation is high $(20 \mathrm{~mm})$, while in some others, the deviation is lower than $10 \mathrm{~mm}$. At Bilbao, Milan, and Millau, almost all methods underestimate the observed values, while at Cagliari and Thessaloniki an overestimation is observed. The main difference between temperature and precipitation diagrams is observed in the line plots. In precipitation the bias correction methods are not able to represent with high accuracy the variability of the observed extreme precipitation. Consequently, in the line plots, the four methods' lines are not able to approach the line of the observed results. This fact can also be observed in the correlation values (Taylor diagrams) which are ranged 
from 0 to 0.3 at all stations and for all methods. Finally, the standard deviation values are similar for most of the studied methods at all stations, while at most of them the scaling method presents the lower values. Similar results are also observed for the RMSE.

\subsubsection{Evaluation with QQ Plots and RMSE Values}

Figure 6 presents the QQ plots of the TMX for the 10 stations which were selected for evaluation. The QQ plot for Rome reveals that both the RegCM4-MPI values and the bias-corrected values (estimated by all methods) differ from the reference point-diagonal line $(\mathrm{x}=\mathrm{y})$. The smallest deviation is observed for the RegCM4-MPI and TIN-copula data sets, while the other three bias correction methods present important biases especially at the lower tail of the diagram. For the stations of Brindisi, Milan, Millau, and Bilbao, the results are similar. Specifically, the RegCM4-MPI TMX lines differ from the diagonal line as the RegCM4-MPI values overestimate the observed ones in all cases. After the bias correction with the TIN-copula, delta, scaling, and EQM methods, the results were improved as the resect lines are close to the diagonal line. The scaling method presents deviation on the upper tail of the diagrams, while the new proposed method is close to the other methods and to the diagonal. In the plot of Cagliari, both the RegCM4-MPI and the bias-corrected values are close to the reference line, while in the upper tail of the graph, a greater diversion from the diagonal line is observed for the TIN-copula and the scaling method. Analyzing the QQ plot at Ierapetra, all the evaluated data sets diverge slightly from the reference line, especially from the middle and the upper tail of the graph. In the lower part, the RegCM4-MPI, the TIN-copula and the delta methods approach more satisfactorily the reference data set, while in the upper tail, the RegCM4-MPI and the scaling method present the biggest deviations. For the station in Nice, the TIN-copula, the scaling, and the EQM methods fall along the diagonal line, while both the RegCM4-MPI and scaling lines present important deviances. Finally, Split and Thessaloniki present similar results. The RegCM4-MPI line overestimates the maximum temperature in the largest part of the graph, while after the bias correction (with all methods) the results have been improved, as their lines are much closer to the diagonal line.

In Figure 7 the QQ plots of TMN for the 10 selected stations are presented. In four of the 10 stations (Rome, Cagliari, Split, Thessaloniki), the values derived from the RegCM4-MPI model (except Cagliari) and the bias correction methods, fall along the diagonal line, as they approach the observed values quite accurately. In the stations of Brindisi, the RegCM4-MPI's line diverge from the reference line in the whole graph, while after the bias correction with the delta, scaling, and EQM methods, the results for the middle and the upper tail of the plot have been improved satisfactorily. The TIN-copula's line presents a small difference from the diagonal line especially in the middle of the graph. At Milan, the RegCM4-MPI and the scaling lines present important differences from the reference line while all the other methods, including the TIN-copula fall along the diagonal. At the station in Millau, all the lines except for the TIN-copula present biases from diagonal in the lower tail. On the contrary, the TIN-copula line presents an important deviation from diagonal in the whole graph. At Bilbao, all methods present biases from the reference line in the lower tail. The RegCM4-MPI and scaling lines overestimate the lower minimum temperature, while the TIN-copula, the delta, and the EQM methods underestimate them. For the highest values of TMN, the RegCM4-MPI and scaling methods satisfactorily approach the observed ones, while the other three methods present deviations. According to the QQ plot of the Ierapetra station, the majority of the methods (lines) deviate from the observed values, while the EQM and delta methods present the biggest differences in the lower part of the graph. Finally, as did also happen with TMX, in the station in Nice, the RegCM4-MPI model's line and the scaling line diverge significantly from the diagonal line, while all the other methods approach with high accuracy the TMN values. 




Figure 7. QQ plots of the evaluated bias correction methods for the 10 selected stations and for minimum mean temperatures (TMN). 
According to the precipitation (R99) QQ plots (Figure 8), in most of the stations, the lines of both the RegCM4-MPI model and the bias correction methods approach satisfactorily the observed values in the lower tail of the graphs. On the contrary, in the middle and especially in the upper tail of the graphs, most of the lines diverge from the diagonal one. Particularly, for the station in Rome, the EQM and the scaling methods present the greatest differences from the lower tail to the middle, while in the upper tail, all methods except for the delta method present important biases. For the station in Brindisi, the results from all the bias correction methods and the RegCM4-MPI model approach satisfactory the diagonal line. In the stations of Milan, Millau, and Nice, the RegCM4-MPI model significantly overestimates the observed values as its line is over the reference line. For the stations of Milan and Nice, the delta method satisfactorily approaches the reference line, the EQM method mainly follows the RegCM4-MPI line, while the TIN-copula and the scaling methods underestimate the observations. For Millau, all the bias correction methods diverge from the diagonal line, with the TIN-copula line presenting the minimum biases. The QQ plot of Bilbao reveals that the EQM method follows the diagonal line without biases from the lower tail to the middle, while both the TIN-copula and the delta methods present satisfactory results in the largest part of the graph. Finally, the scaling method presents important biases from the diagonal line as it also happens with the RegCM4-MPI from the lower tail to the middle of the graph. However, the RegCM4-MPI presents the best approach for the upper tail of the diagram. At Cagliari, the observed precipitation values are approached by the RegCM4-MPI model until the middle values, while in the upper tail there is an important overestimation. After the bias correction, the results differ from the reference line, with the EQM method presenting the greatest biases. In the upper tail of the graph, all the lines of the bias correction methods present better results compared with the middle and lower values. For the station in Ierapetra, the RegCM4-MPI and scaling method present the worst results as they differ significantly from the diagonal line. On the contrary, the delta and TIN-copula methods lines follow the reference line with only small deviations in the lower tail. The EQM overestimates the results in the biggest part of the diagram. At Nice, the RegCM4-MPI model present similar behavior with the EQM method as both lines overestimate the observations. On the contrary, the TIN-copula and scaling lines underestimate the observations. The best results are achieved by the delta method. At the station in Split, the RegCM4-MPI, the scaling, and the EQM lines differ from the reference line, while the delta and the TIN-copula lines follow across the diagonal. In the upper tail of the graph, all methods present biases, with the TIN-copula method presents the smallest. Finally, the Thessaloniki QQ plot shows that the RegCM4-MPI, TIN-copula, and scaling method lines approach with high accuracy the reference line, while the EQM and delta methods present biases which are greatest in the upper tail of the graph.

Figure 9 presents the RMSE of TMX for the 10 stations which have been selected for evaluation. At most of the stations (six), the RMSE between the observed TMX and the MPI's values is the greatest compared with the bias correction methods. The proposed TIN-copula method presents satisfactory results, as its value is almost equal with the results from the delta and EQM methods and is the lowest for most of the stations. Specifically, for the stations of Brindisi, Milan, Bilbao, Ierapetra, Split, and Thessaloniki all the bias correction methods produce almost equal results, which are much lower compared with the MPI values. For the station in Rome, the TIN-copula method has a RMSE value equal to five while all the other methods have double that value. At the station in Nice, the RMSE between the observations and the MPI model is almost 10, while the respective values of all the other bias correction methods (except for scaling) are lower than five. However, the scaling method presents the highest RMSE value which is equal to 15. At Cagliari, the TIN-copula method has an RMSE value one degree higher than the other methods. 


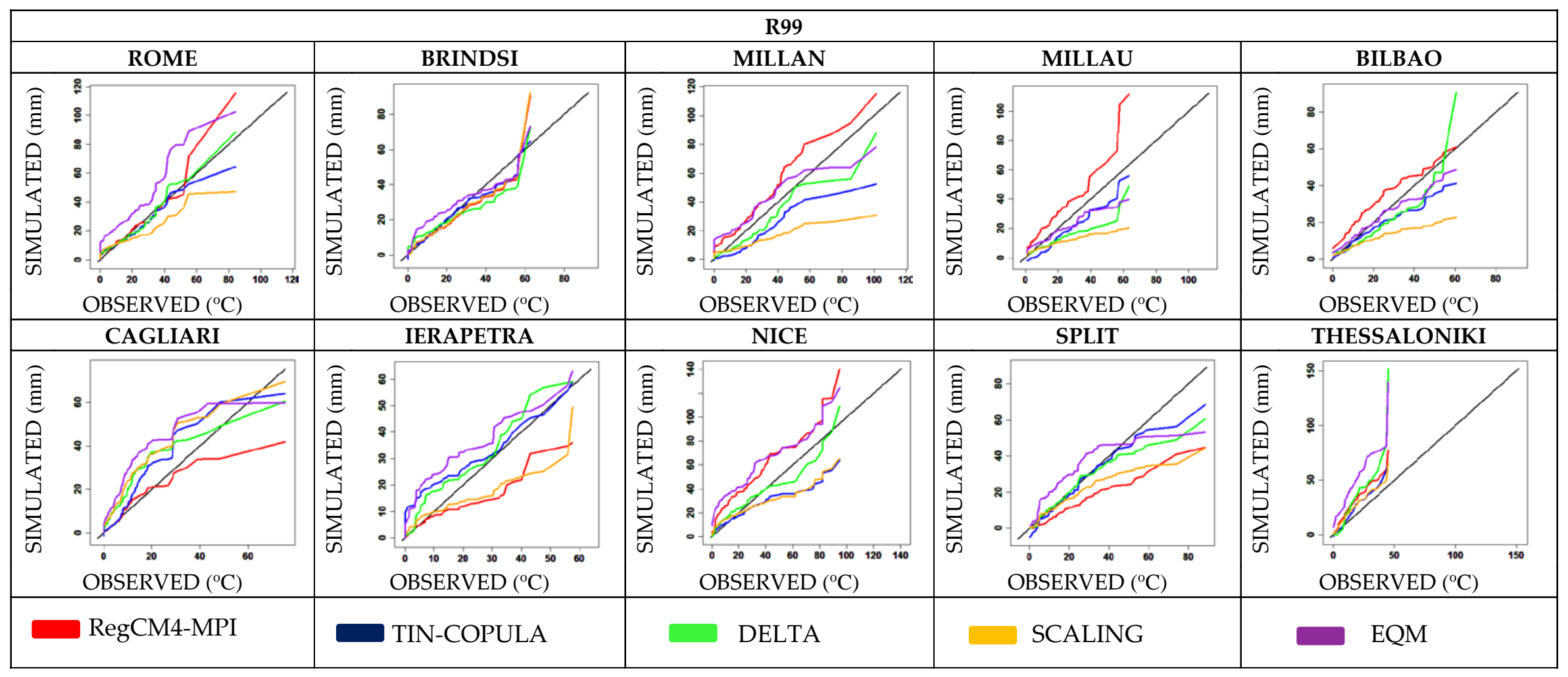

Figure 8. QQ plots of the evaluated bias correction methods for the 10 selected stations and extreme precipitation (R99). 


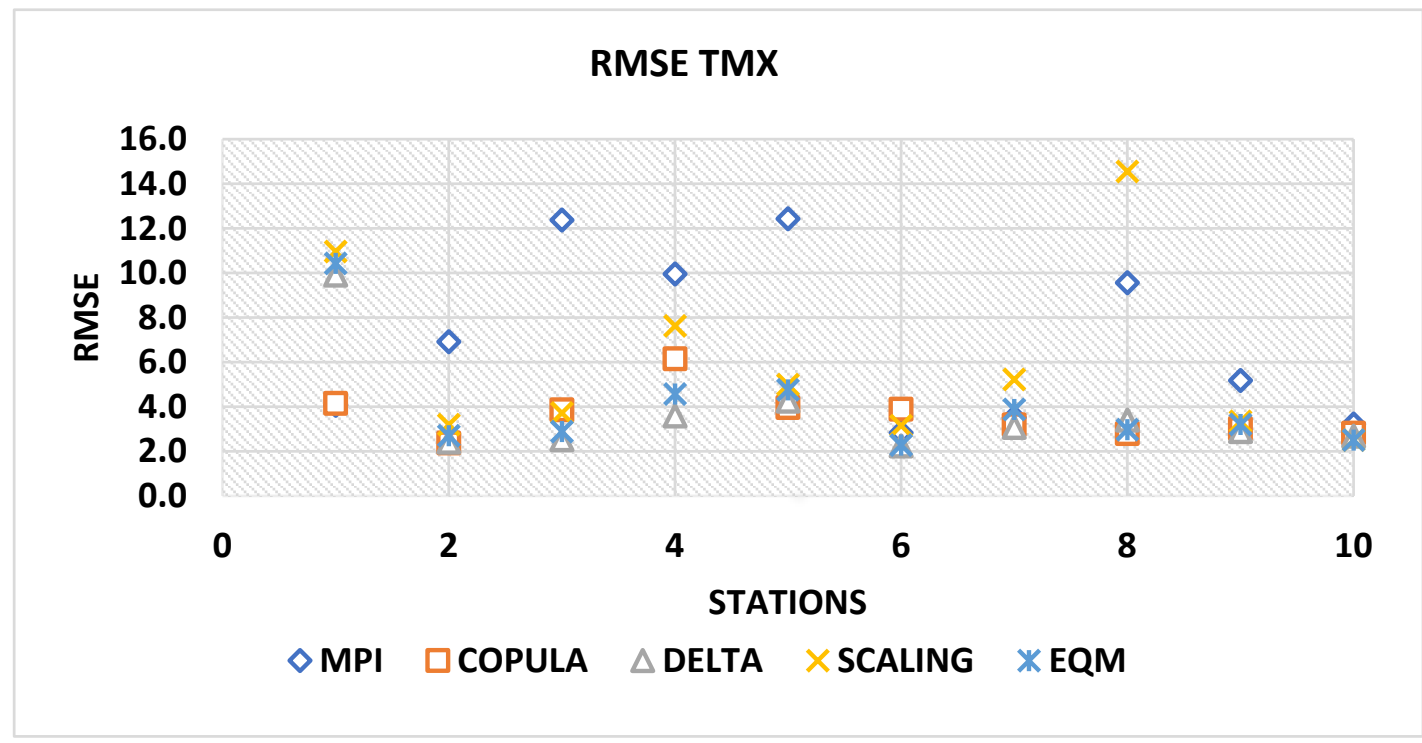

Figure 9. The RMSE value for the 10 stations and for maximum mean temperatures (TMX). (1: Rome, 2: Brindisi, 3: Milan, 4: Millau, 5: Bilbao, 6: Cagliari, 7: Ierapetra, 8: Nice, 9: Split, 10: Thessaloniki).

The RMSE results for TMN (Figure 10) present similarities with the corresponding results of the TMX. At the majority of stations, all the bias correction values, as well as the RegCM4-MPI values, have a similar RMSE value. Some differences are observed at the station in Milan where the RegCM4-MPI model has an RMSE value equal to 10, while the value from the scaling method is much higher (19). Furthermore, at Millau, the TIN-copula method has an RMSE value almost two degrees greater than the other methods. Finally, in Nice, the RegCM4-MPI and the scaling method have RMSE values much higher than the other methods.

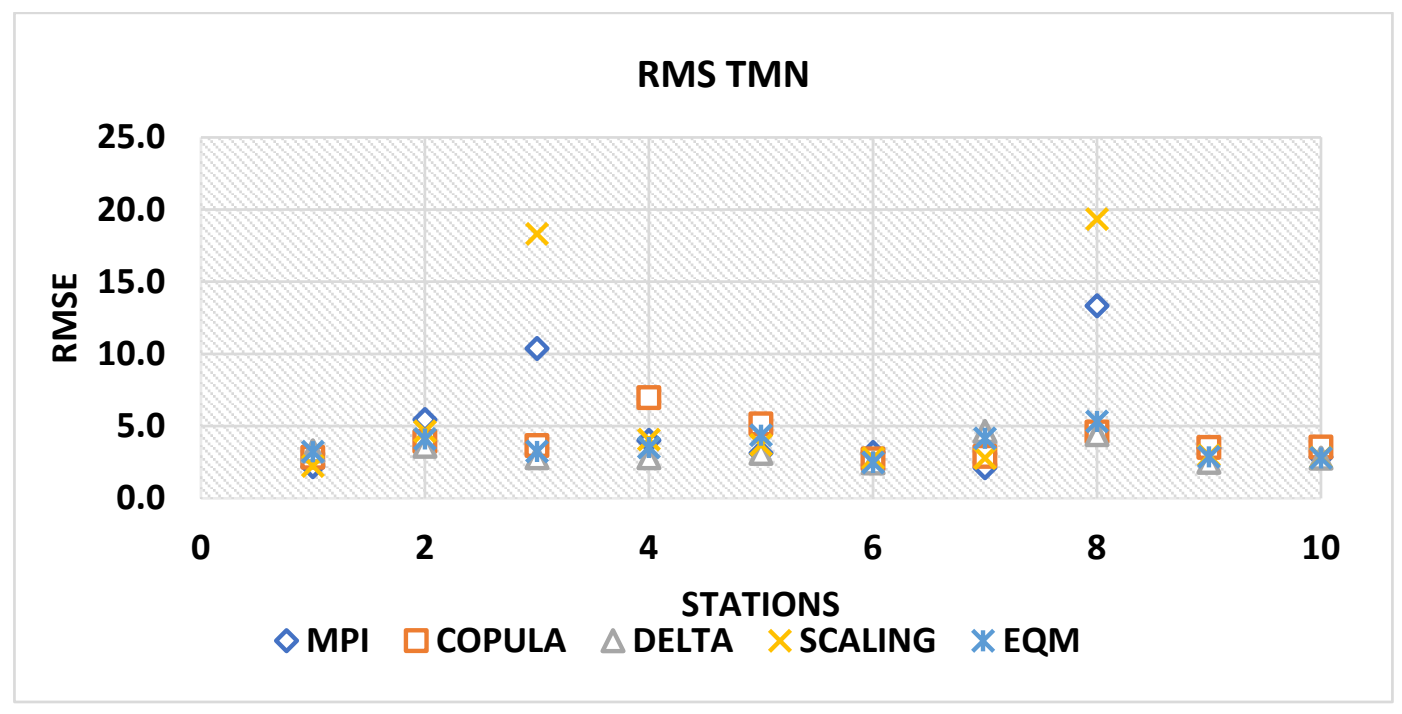

Figure 10. The RMSE value for the 10 stations and for minimum mean temperatures (TMN). (1: Rome, 2: Brindisi, 3: Milan, 4: Millau, 5: Bilbao, 6: Cagliari, 7: Ierapetra, 8: Nice, 9: Split, 10: Thessaloniki).

Figure 11 shows the comparison of the RMSE values of the R99 for the 10 evaluated stations. The MPI model presents the highest RMSE values at half of the studied stations (Brindisi, Milan, Millau, Bilbao, Split). The TIN-copula method presents satisfactory results for all stations, as its RMSE is low compared with the other methods in most of the stations. Despite the fact that in the TMX and TMN diagrams, the scaling method has high RMSE values (compared with the other methods), for the R99, 
the results of this method are satisfactory and almost equal with the TIN-copula results. Analyzing the delta method, Figure 10 shows that in the majority of stations its RMSE value is almost equal with the other bias correction methods, while this method presents a high RMSE at the stations of Nice and Thessaloniki. Finally, the EQM method has a RMSE value similar to the other methods in six of the ten stations, while in the remaining four stations, this method has the greatest RMSE value (Rome, Cagliari, Nice, Thessaloniki).

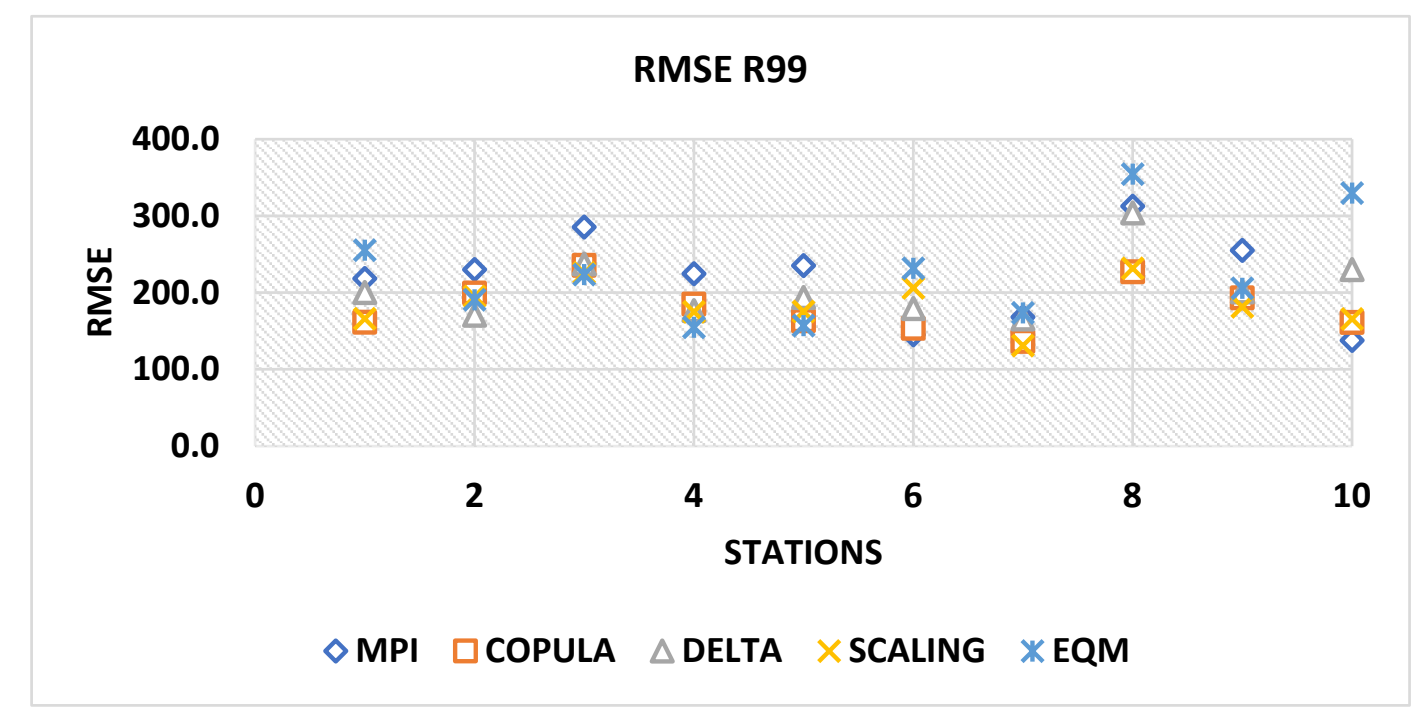

Figure 11. The RMSE value for the 10 stations and for extreme precipitation (R99). (1: Rome, 2: Brindisi, 3: Milan, 4: Millau, 5: Bilbao, 6: Cagliari, 7: Ierapetra, 8: Nice, 9: Split, 10: Thessaloniki).

\section{Discussion and Conclusions}

The scope of the present study is to introduce and evaluate a new statistical method for the bias correction of extreme temperature and precipitation values of regional climate models. The new method combines the triangular irregular network and the copula method, and is called TIN-copula method. For the evaluation of the results of the TIN-copula method, the bias-corrected values are compared with both the results of three other widely used bias correction methods (delta, scaling and empirical quantile mapping) and with the observed values of the closest station. In the present study, daily values of temperature and precipitation, as well as monthly extreme indices (temperature: TMX, TMN, and precipitation: R99) covering the period from 1981 to 2000 for Europe were used. The used data came from two sources; station data from ECA\&D, and data from the regional climate model RegCM4, which uses its initial values from the General Circulation model MPI. The four bias correction methods are applied to the RegCM4-MPI values and the station data are used as reference ones.

The evaluation of well-known or newly introduced bias correction methods was the subject of several studies, as it is an important issue in climatology. In 2013, Lafon et al. [8] compared four bias correction methods (linear, non-linear, empirical quantile mapping) for the bias correction of RCM daily precipitation in the region of Great Britain. The results show that the linear method (which includes the delta method) presents the weakest correction while the empirical quantile mapping showed the most comprehensive correction. For the parameter of temperature, the quantile mapping approach was modified and improved for extremes by Thrasher et al. [11] with successful results.

The present study shows that the results of each method are influenced both by the studied parameter as well as by the location of the studied grids. Firstly, the results showed that the RegCM4-MPI model's values needed correction as there are biases for all parameters and for the majority of stations. Particularly, the simulated maximum mean temperatures underestimate the observed ones in all stations, as also happens in six of the ten stations for the minimum mean temperatures. Additionally, in the same stations which are located in the western part of the Mediterranean (except for Thessaloniki), 
there is an overestimation of their extreme precipitations. This is in accordance with previous studies that have mentioned that the estimated precipitation amounts in the Mediterranean region are, in general, overestimated by climate models [40,41]. In order to increase the accuracy of these estimations, the delta, scaling, EQM, and the TIN-copula methods have been applied.

For TMX, the results of the proposed method present similarities with both the EQM and the delta method. All methods approach the extreme values which cover $25 \%-75 \%$ of the whole data set with high accuracy. However, the accuracy is lower for the highest and lowest values. This differs for the scaling method as it presents significant biases for all values. On the other hand, for TMN, the majority of stations presents similar results, however, the approach accuracy is lower with respect to the TMX. Finally, it should be highlighted that both for TMX and TMN, the variability and the correlation of the bias-corrected values present significant similarities with the observed ones. In the case of R99 beinga stochastic variable, the results are totally different, with significant discrepancies varying from station to station and from method to method.

Taking into account the results for all parameters and stations, the TIN-copula method presents highly accurate results, which are close to the results of the other methods in some cases or much better in some others. Additionally, the TIN-copula method has some important advantages compared with the delta, scaling, and empirical quantile mapping methods:

- Firstly, the bias correction with the TIN-copula method can be achieved at every x_point, which is included in a formatted triangle, while the other methods can be applied only at specific points, where observed data exist and used as defaults.

- The second main advantage is that the TIN-copula method uses three neighboring stations for the bias correction of the x-point and not only one as the other methods do. The TIN-copula method and the other methods can present some discouraging results when the climatology of the default station differs importantly from the tested stations. However, the TIN-copula method provides a more robust result, as the three stations can provide better characteristics of the climate of the study region.

- Another advantage of the proposed method is that the whole time period is used, while in the other bias correction methods, sub-time periods are used.

- Additionally, an important advantage of the TIN-copula method is that the estimated new TIN-copula function can be calculated once, meaning that it is unique for each x_point and that it can then be used for different datasets.

- Finally, since in TIN-copula method a specific function is estimated for the studied region, this function is stable also for the future. Consequently, it can be used for the bias correction of the extreme climate model's values for future periods.

In conclusion, based on the results of the present study, it is proposed that the TIN-copula method can be considered as an accurate tool for the bias correction of regional climate models' values as its results are accurate and present some important advantages compared with other bias correction methods. Finally, as the TIN-copula is a newly introduced method, further analysis of this as well as its application in several areas, time periods, and climate parameters are proposed.

Author Contributions: All authors contributed equally in carrying out this research work and writing the paper. All authors have read and agree to the published version of the manuscript.

Funding: This research is co-financed by Greece and the European Union (European Social Fund- ESF) through the Operational Programme (Human Resources Development, Education and Lifelong Learning) in the context of the project "Strengthening Human Resources Research Potential via Doctorate Research" (MIS-5000432), implemented by the State Scholarships Foundation (IK $\Upsilon$ ).

Acknowledgments: The auhors would like to acknowledge the data providers in the ECA\&D project. Klein Tank, A.M.G. and Coauthors, 2002. Daily dataset of 20th-century surface air temperature and precipitation series for the European Climate Assessment. Int. J. of Climatol.,22, 1441-1453. Data and metadata available at https://www.ecad.eu. Additionally the authors would like to thank the two reviewers for their useful comments and suggestions. 
Conflicts of Interest: The authors declare no conflict of interest.

\section{Appendix A}

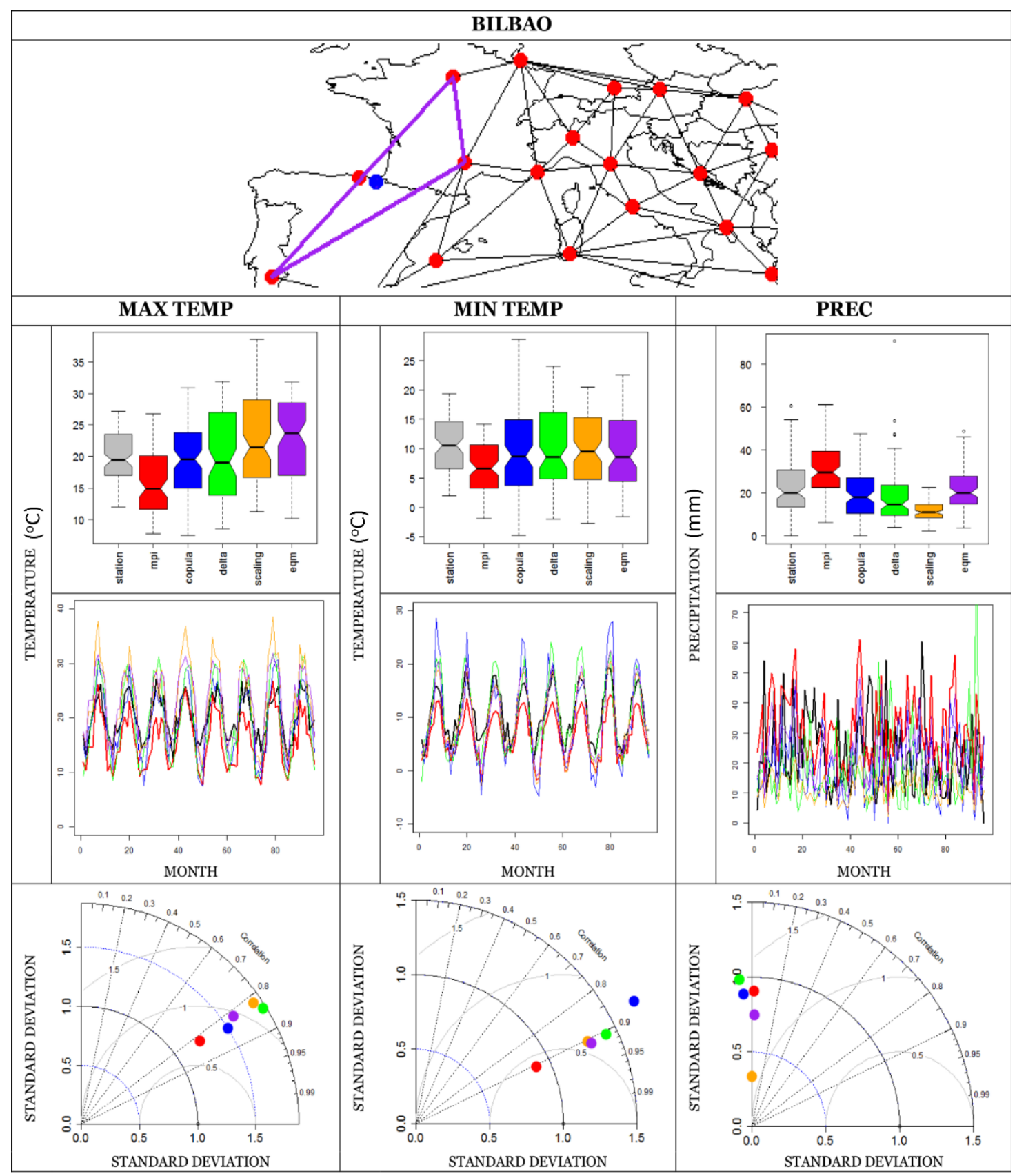

Figure A1. The map of the figure shows the location of the reference station (red point), the closest RegCM4-MPI grid (blue point) and the triangle which includes these points (purple triangle). The boxplots, line plots, and Taylor diagrams present a comparison between the observed, the model's, and the bias-corrected values (with the four methods) for the three studied parameters (TMX, TMN, R99). In the diagrams, there is a correspondence between the colors and the presented data sets: Grey $=$ Observations Red $=$ RegCM4-MPI, Blue $=$ TIN-copula, Green $=$ Delta, Orange $=$ Scaling, Purple = EQM. 


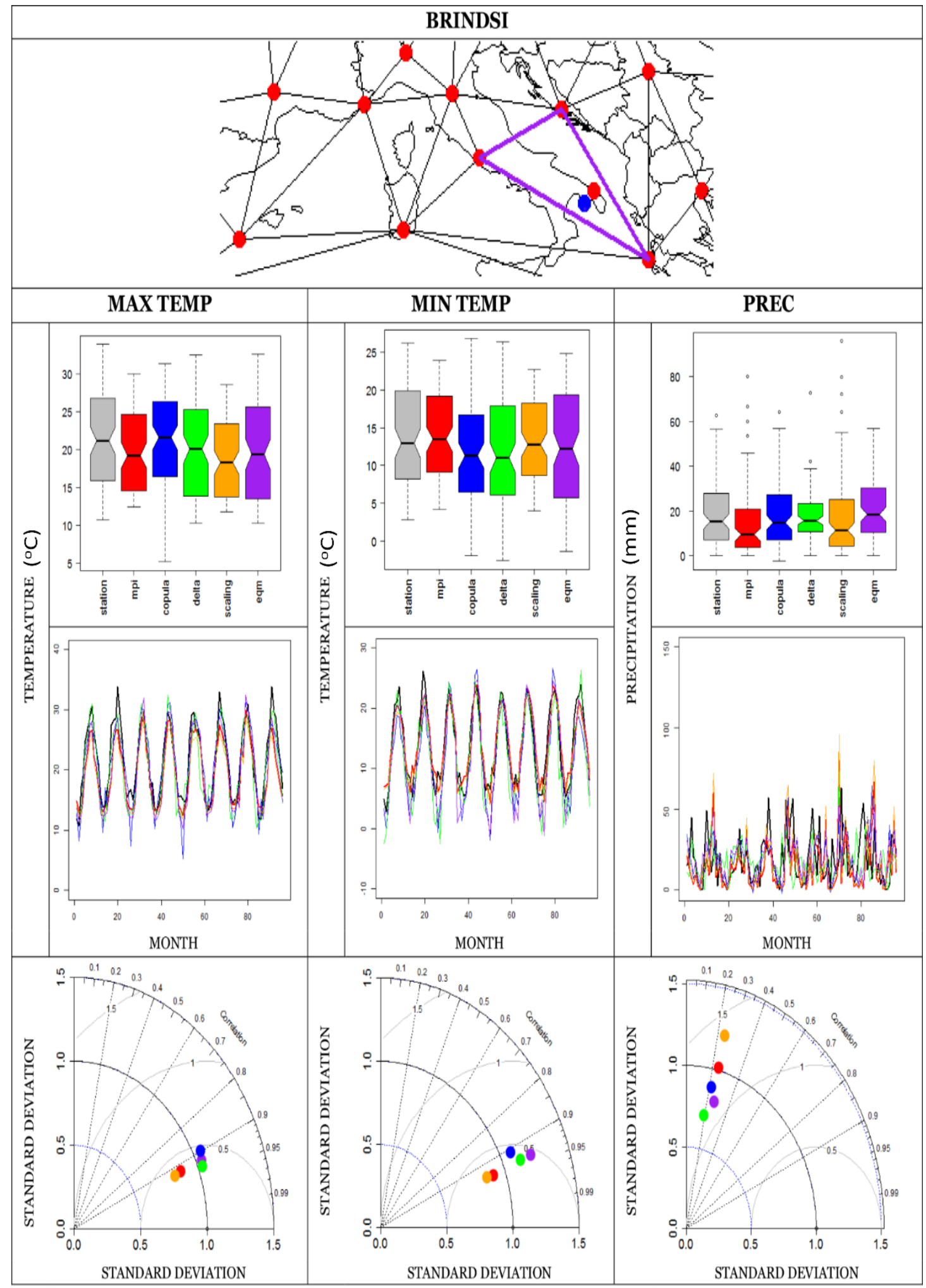

Figure A2. The map of the figure shows the location of the reference station (red point), the closest RegCM4-MPI grid (blue point) and the triangle which includes these points (purple triangle). The boxplots, line plots, and Taylor diagrams present a comparison between the observed, the model's, and the bias-corrected values (with the four methods) for the three studied parameters (TMX, TMN, R99). In the diagrams, there is a correspondence between the colors and the presented data sets: Grey $=$ Observations Red = RegCM4-MPI, Blue = TIN-copula, Green = Delta, Orange = Scaling, Purple $=$ EQM 


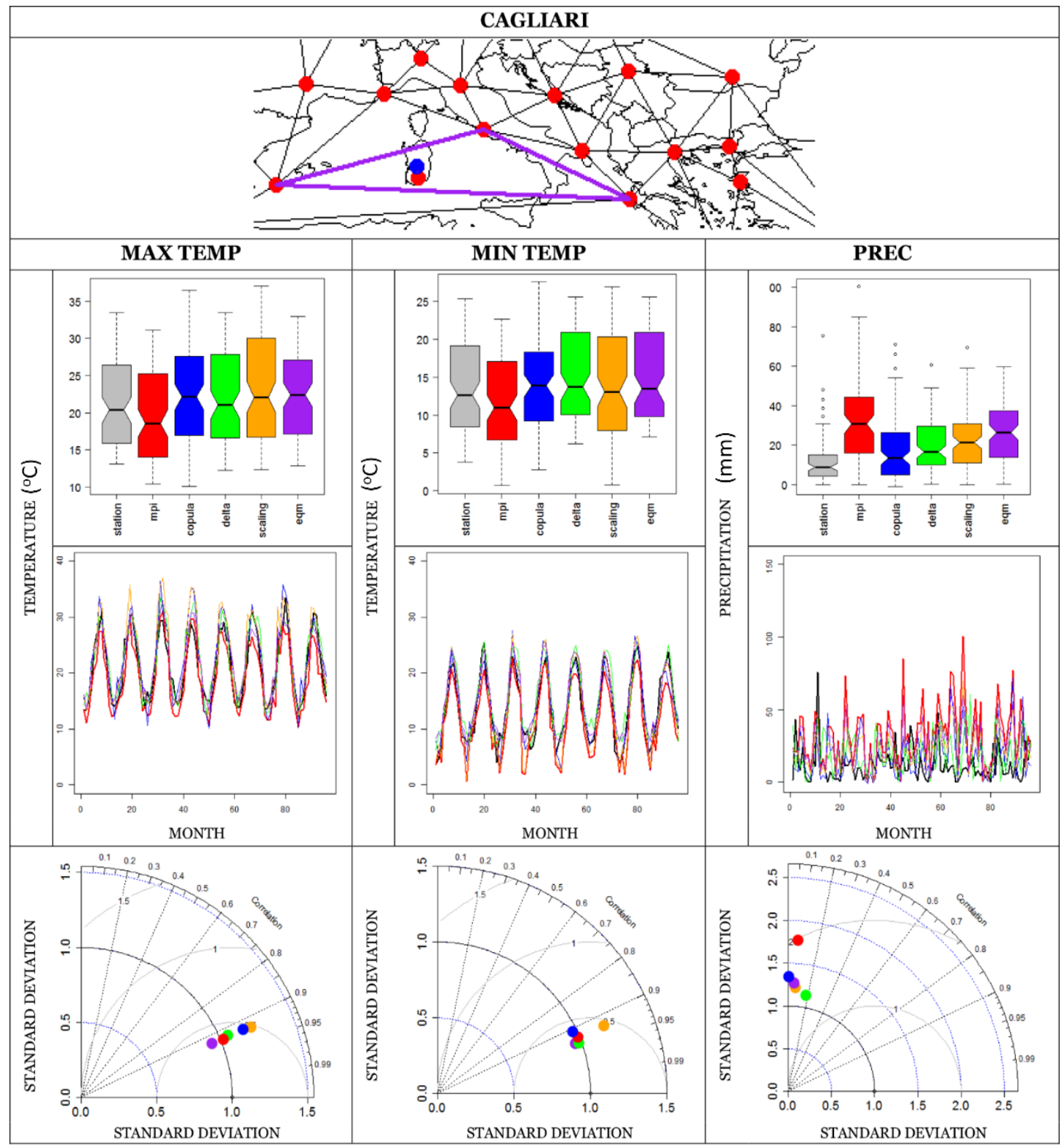

Figure A3. The map of the figure shows the location of the reference station (red point), the closest RegCM4-MPI grid (blue point) and the triangle which includes these points (purple triangle). The boxplots, line plots, and Taylor diagrams present a comparison between the observed, the model's, and the bias-corrected values (with the four methods) for the three studied parameters (TMX, TMN, R99). In the diagrams, there is a correspondence between the colors and the presented data sets: Grey $=$ Observations Red $=$ RegCM4-MPI, Blue = TIN-copula, Green = Delta, Orange $=$ Scaling, Purple $=$ EQM . 


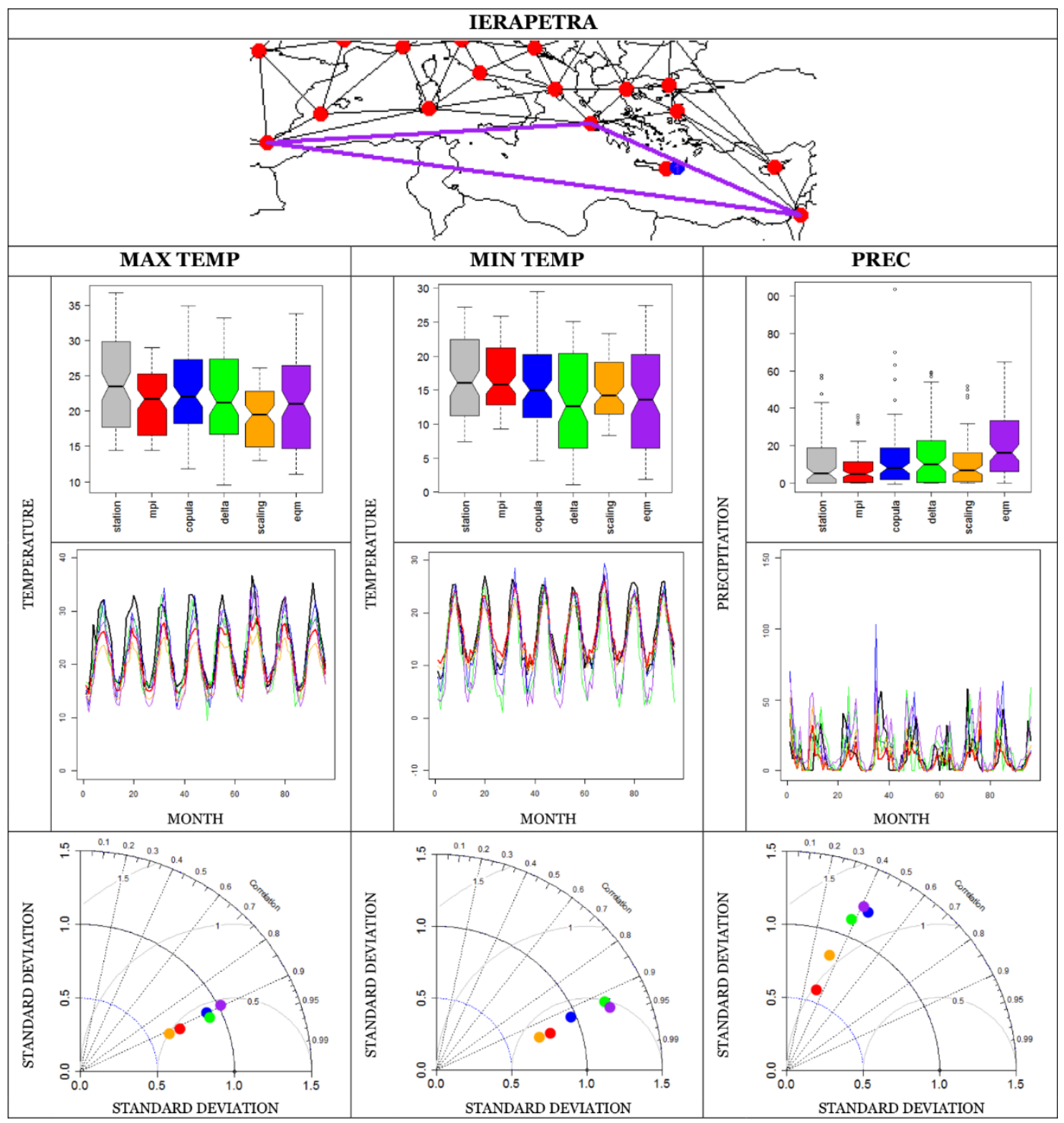

Figure A4. The map of the figure shows the location of the reference station (red point), the closest RegCM4-MPI grid (blue point) and the triangle which includes these points (purple triangle). The boxplots, line plots, and Taylor diagrams present a comparison between the observed, the model's, and the bias-corrected values (with the four methods) for the three studied parameters (TMX, TMN, R99). In the diagrams, there is a correspondence between the colors and the presented data sets: Grey $=$ Observations Red $=$ RegCM4-MPI, Blue = TIN-copula, Green = Delta, Orange = Scaling, Purple $=$ EQM. 




Figure A5. The map of the figure shows the location of the reference station (red point), the closest RegCM4-MPI grid (blue point) and the triangle which includes these points (purple triangle). The boxplots, line plots, and Taylor diagrams present a comparison between the observed, the model's, and the bias-corrected values (with the four methods) for the three studied parameters (TMX, TMN, R99). In the diagrams, there is a correspondence between the colors and the presented data sets: Grey $=$ Observations Red $=$ RegCM4-MPI, Blue = TIN-copula, Green = Delta, Orange $=$ Scaling, Purple $=$ EQM. 


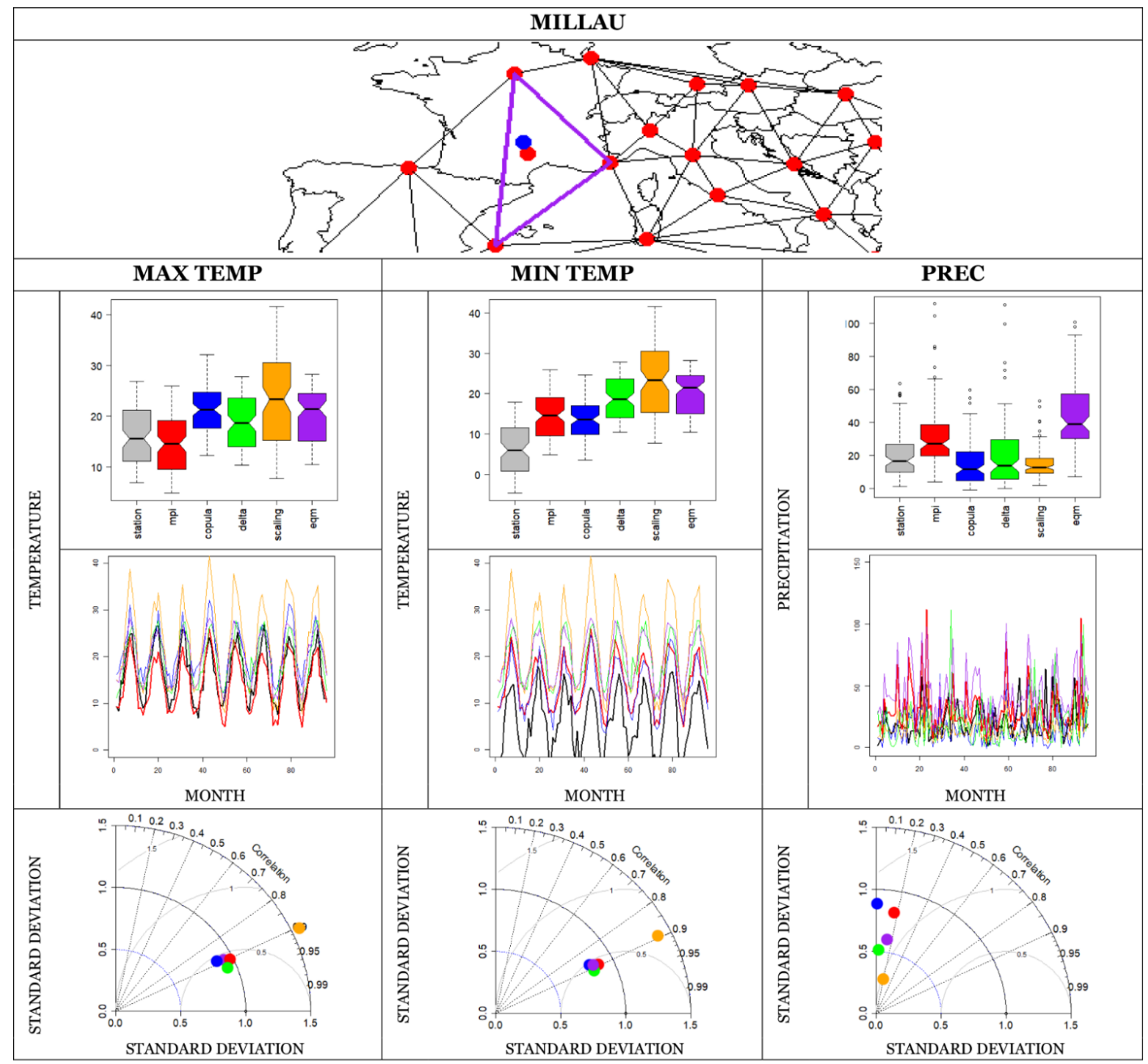

Figure A6. The map of the figure shows the location of the reference station (red point), the closest RegCM4-MPI grid (blue point) and the triangle which includes these points (purple triangle). The boxplots, line plots, and Taylor diagrams present a comparison between the observed, the model's, and the bias-corrected values (with the four methods) for the three studied parameters (TMX, TMN, R99). In diagrams, there is a correspondence between the colors and the presented data sets: Grey $=$ Observations Red $=$ RegCM4-MPI, Blue = TIN-copula, Green = Delta, Orange $=$ Scaling, Purple $=$ EQM . 


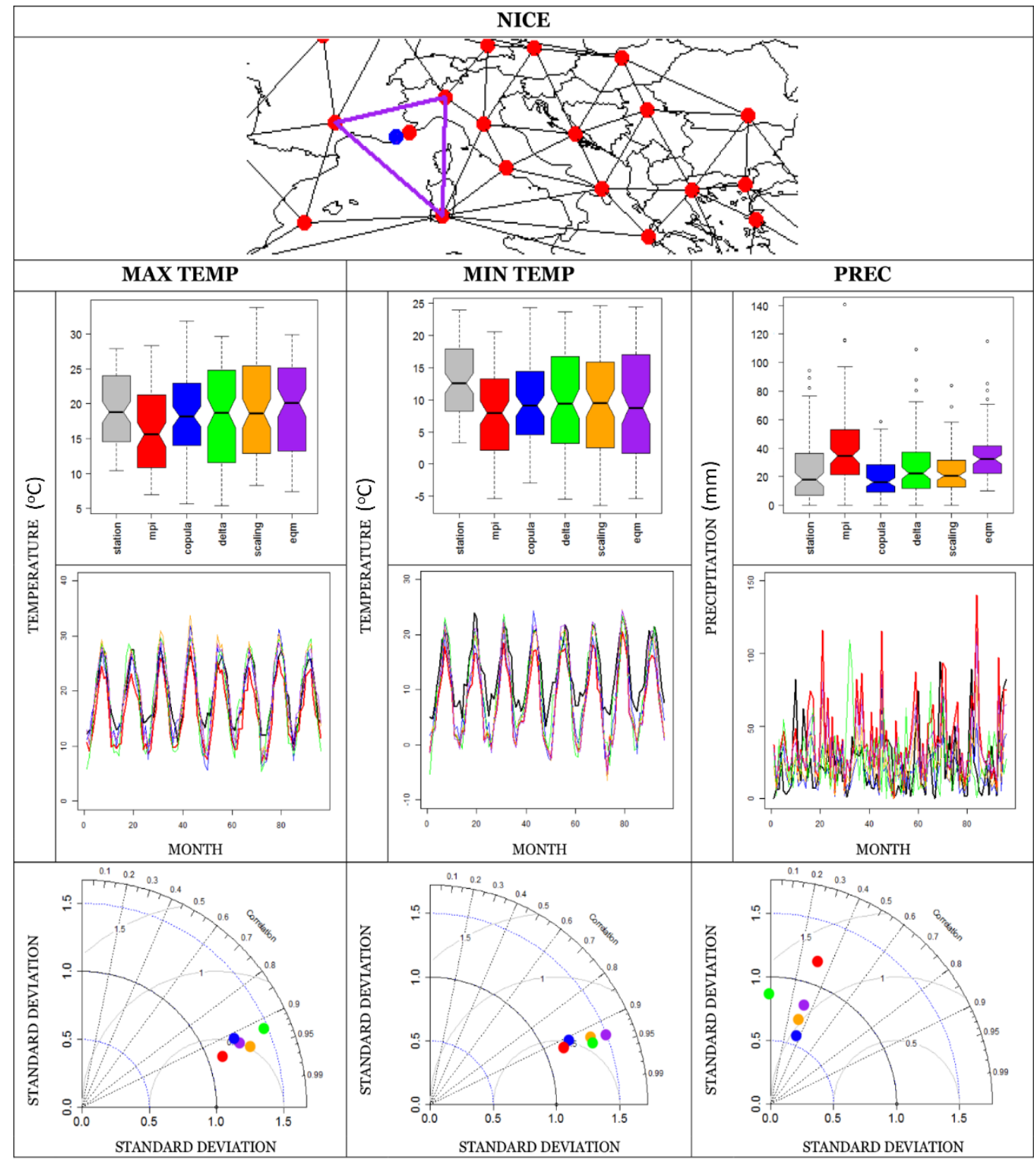

Figure A7. The map of the figure shows the location of the reference station (red point), the closest RegCM4-MPI grid (blue point) and the triangle which includes these points (purple triangle). The boxplots, line plots, and Taylor diagrams present a comparison between the observed, the model's, and the bias-corrected values (with the four methods) for the three studied parameters (TMX, TMN, R99). In the diagrams, there is a correspondence between the colors and the presented data sets: Grey $=$ Observations Red $=$ RegCM4-MPI, Blue = TIN-copula, Green = Delta, Orange = Scaling, Purple $=$ EQM 


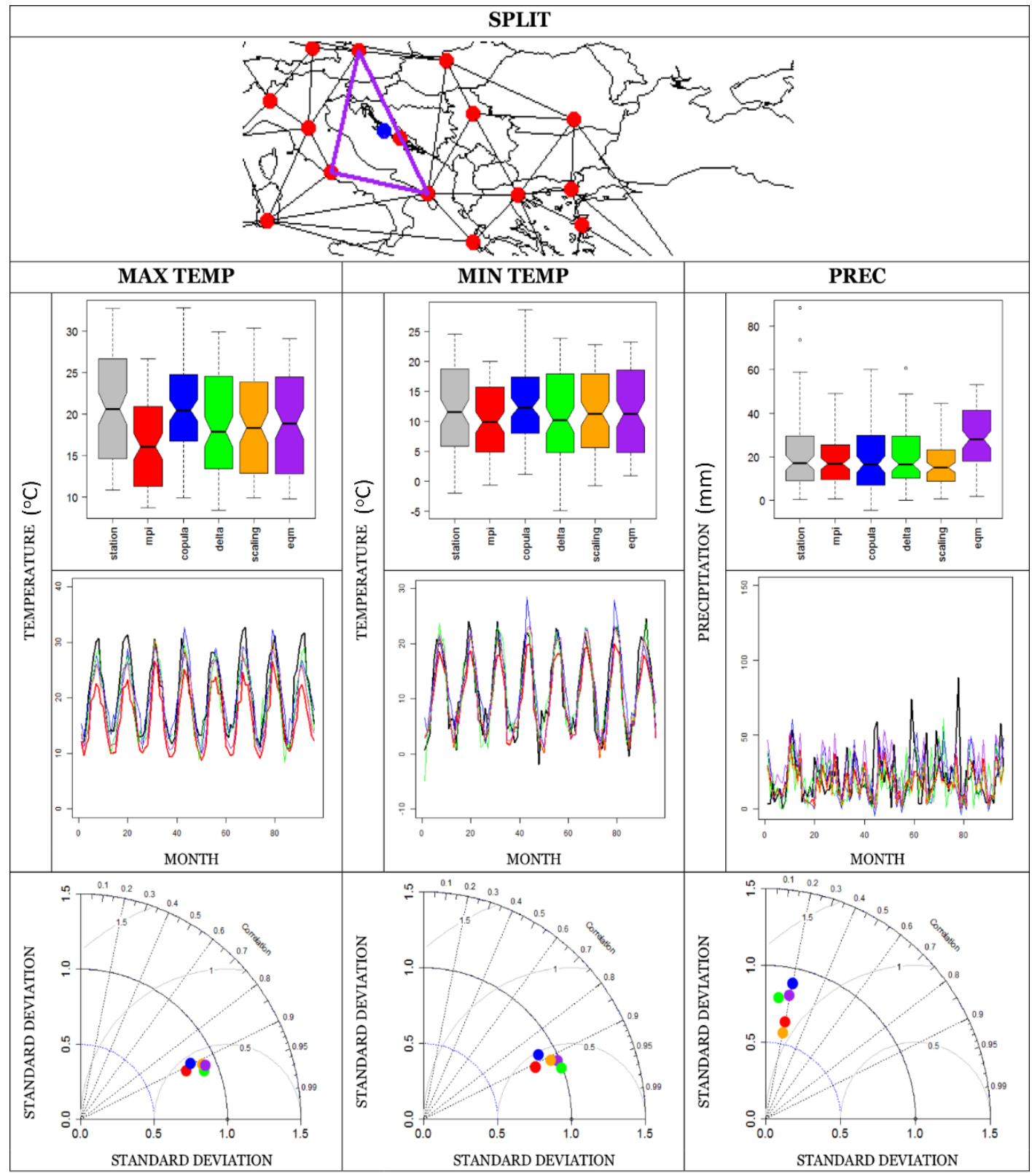

Figure A8. The map of the figure shows the location of the reference station (red point), the closest RegCM4-MPI grid (blue point) and the triangle which includes these points (purple triangle). The boxplots, line plots, and Taylor diagrams present a comparison between the observed, the model's, and the bias-corrected values (with the four methods) for the three studied parameters (TMX, TMN, R99). In the diagrams, there is a correspondence between the colors and the presented data sets: Grey = Observations, Red = RegCM4-MPI, Blue = TIN-copula, Green = Delta, Orange = Scaling, Purple $=$ EQM. 


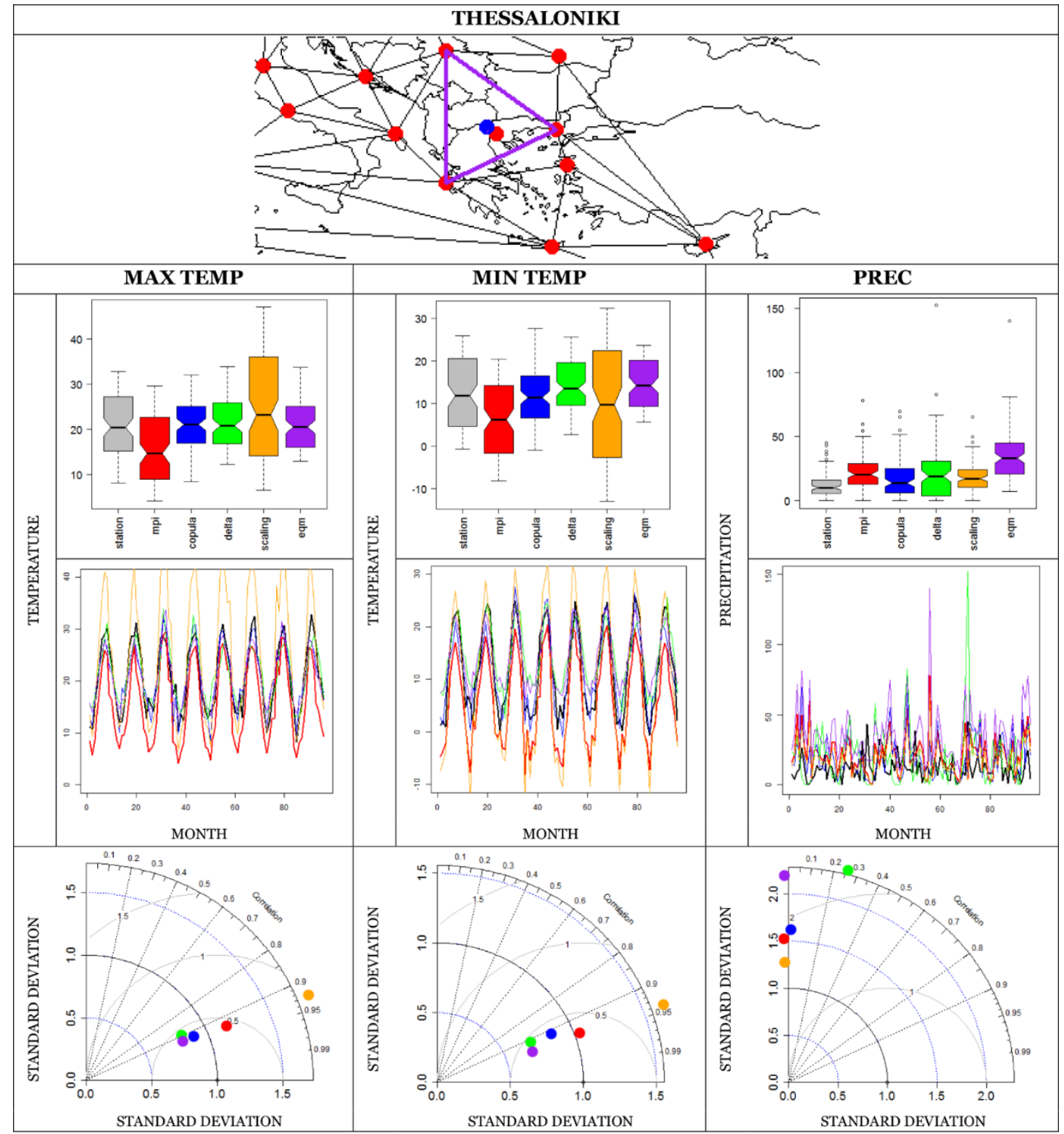

Figure A9. The map of the figure shows the location of the reference station (red point), the closest RegCM4-MPI grid (blue point) and the triangle which includes these points (purple triangle). The boxplots, line plots, and Taylor diagrams present a comparison between the observed, the model's, and the bias-corrected values (with the four methods) for the three studied parameters (TMX, TMN, R99). In the diagrams, there is a correspondence between the colors and the presented data sets: Grey $=$ Observations, Red $=$ RegCM4-MPI, Blue = TIN-copula, Green = Delta, Orange $=$ Scaling, Purple $=$ EQM .

\section{References}

1. World Modeling Summit for Climate Prediction. 2008. Available online: http://wcrp.ipsl.jussieu.fr/ Workshops/ModellingSummit/Documents/FinalSummitStat_6_6.pdf (accessed on 15 May 2009).

2. Christensen, J.H.; Christensen, O.B. A summary of the PRUDENCE model projections of changes in European climate by the end of this century. Clim. Chang. 2007, 81 (suppl. S1), 7-30. [CrossRef]

3. Mearns, L.O.; Arritt, R.; Biner, S.; Bukovsky, M.S.; McGinnis, S.; Sain, S.; Caya, D.; Correia, J., Jr.; Flory, D.; Gutowski, W.; et al. The North American Regional Climate Change Assessment Program: Overview of phase I results. Bull. Am. Meteorol. Soc. 2012, 93, 1337-1362. [CrossRef] 
4. Sillmann, J.; Kharin, V.; Zhang, X.; Zwiers, F.; Bronaugh, D. Climate extremes indices in the CMIP5 multimodel ensemble: Part 1. Model evaluation in the present climate. J. Geophys. Res. Atmos. 2013, 118, 1716-1717. [CrossRef]

5. Sharma, D.; Das Gupta, A.; Babel, M.S. Spatial disaggregation of Bias-corrected GCM precipitation for improved hydrologic simulation: Ping river basin, Thailand. Hydrol. Earth Syst. Sci. 2007, 11, 1373-1390. [CrossRef]

6. Hansen, J.W.; Challinor, A.; Ines, A.; Wheeler, T.; Moronet, V. Translating forecasts into agricultural terms: Advances and challenges. Clim. Res. 2006, 33, 27-41. [CrossRef]

7. Johnson, F.; Sharma, A. A nesting model for bias correction of variability at multiple time scales in general circulation model precipitation simulations. Water Resour. Res. 2012, 48, W01504. [CrossRef]

8. Lafon, T.; Dadson, S.; Buys, G.; Prudhomme, C. Bias correction of daily precipitation simulated by a regional climate model: A comparison of methods. Int. J. Climatol. 2013, 33, 1367-1381. [CrossRef]

9. Chen, J.; Brissette, F.P.; Chaumont, D.; Braun, M. Finding appropriate bias correction methods in downscaling precipitation for hydrologic impact studies over North America. Water Resour. Res. 2013, 49, 4187-4205. [CrossRef]

10. Cannon, A.J.; Sobie, S.R.; Murdock, T.Q. Bias correction of GCM precipitation by quantile mapping: How well do methods preserve changes in quantiles and extremes? J. Clim. 2015, 28, 6938-6959. [CrossRef]

11. Thrasher, B.; Maurer, E.P.; Duffy, P.B.; McKellar, C. Technical Note: Bias correcting climate model simulated daily temperature extremes with quantile mapping. Hydrol. Earth Syst. Sci. 2012, 16, 3309-3314. [CrossRef]

12. Navarro-Racines, C.E.; Tarapues-Montenegro, J.E.; Ramírez-Villegas, J.A. Bias-correction in the CCAFS-Climate. In Portal: A Description of Methodologies. Decision and Policy Analysis (DAPA) Research Area; International Center for Tropical Agriculture (CIAT): Cali, Colombia, 2015.

13. Eisner, S.; Voss, F.; Kynast, E. Statistical bias correction of global climate projections-consequences for large scale modeling of flood flows. Adv. Geosci. 2012, 31, 75-82. [CrossRef]

14. Tabor, K.; Williams, J.W. Globally downscaled climate projections for assessing the conservation impacts of climate change. Ecol. Appl. 2010, 20, 554-565. Available online: http://ccr.aos.wisc.edu/publications/pdfs/ globaldownscale.pdf (accessed on 15 August 2015). [CrossRef] [PubMed]

15. Xu, Y. Hyfo: Hydrology and Climate Forecasting. R Package Version 1.4.0 2018. Available online: https://CRAN.R-project.org/package=hyfo (accessed on 27 September 2018).

16. Hawkins, E.; Osborne, T.M.; Ho, C.K.; Challinor, A.J. Calibration and bias correction of climate projections for crop modelling: An idealised case study over Europe. Agric. For. Meteorol. 2013, 170, 19-31. [CrossRef]

17. Olsson, J.; Berggren, K.; Olofsson, M.; Viklander, M. Applying climate model precipitation scenarios for urban hydrological assessment: A case study in Kalmar City, Sweden. Atmos. Res. 2009, 92, 364-375. [CrossRef]

18. Shrestha, M.; Acharya, S.C.; Shrestha, P.K. Bias correction of climate models for hydrological modelling-are simple methods still useful. Meteorol. Appl. 2017, 24, 531-539. [CrossRef]

19. Ines, A.V.M.; Hansen, J.W. Bias correction of daily GCM rainfall for crop simulation studies. Agric. For. Meteorol. 2006, 138, 44-53. [CrossRef]

20. Themeßl, M.J.; Gobiet, A.; Heinrich, G. Empirical-statistical downscaling and error correction of daily precipitation from regional climate models. Int. J. Climatol. 2011, 31, 1530-1544. [CrossRef]

21. Panofsky, H.A.; Brier, G. Some Applications of Statistics to Meteorology; The Pennsylvania State University: Pennsylvania, PA, USA, 1968; p. 224.

22. Zhang, L.; Singh, V.P. Bivariate rainfall frequency distributions using Archimedean copulas. J. Hydrol. 2007, 332, 93-109. [CrossRef]

23. Lazoglou, G.; Anagnostopoulou, C.; Skoulikaris, C.; Tolika, K. Bias Correction of Climate Model's Precipitation Using the Copula Method and Its Application in River Basin Simulation. Water 2019, 11, 600. [CrossRef]

24. Mao, G.; Vogl, S.; Laux, P.; Wagner, S.; Kunstmann, H. Stochastic bias correction of dynamically downscaled precipitation fields for Germany through Copula-based integration of gridded observation data. Hydrol. Earth Syst. Sci. 2015, 19, 1787-1806. [CrossRef]

25. Piani, C.; Haerter, J.O. Two dimensional bias correction of temperature and precipitation copulas in climate models. Geophys. Res. Lett. 2012. [CrossRef]

26. Piani, C.; Haerter, J.O.; Coppola, E. Statistical bias correction for daily precipitation in regional climate models over Europe. Theor. Appl. Climatol. 2010, 99, 187-192. [CrossRef] 
27. Watanabe, S.; Kanae, S.; Seto, S.; Yeh, P.J.F.; Hirabayashi, Y.; Oki, T. Intercomparison of bias-correction methods for monthly temperature and precipitation simulated by multiple climate models. J. Geophys. Res. Atmos. 2012. [CrossRef]

28. Cannon, A.J. Multivariate quantile mapping bias correction: An N-dimensional probability density function transform for climate model simulations of multiple variables. Clim. Dyn. 2018, 50, 31-49. [CrossRef]

29. Colette, A.; Vautard, R.; Vrac, M. Regional climate downscaling with prior statistical correction of the global climate forcing. Geophys. Res. Lett. 2012. [CrossRef]

30. Klein Tank, A.M.G.; Wijngaard, J.B.; Können, G.P.; Böhm, R.; Demarée, G.; Gocheva, A.; Mileta, M.; Pashiardis, S.; Hejkrlik, L.; Kern-Hansen, C.; et al. Daily dataset of 20th-century surface air temperature and precipitation series for the European Climate Assessment. Int. J. Climatol. 2002, 22, 1441-1453. [CrossRef]

31. Giorgi, F.; Coppola, E.; Solmon, F.; Mariotti, L.; Sylla, M.B.; Bi, X.; Elguindi, N.; Diro, G.T.; Nair, V.S.; Giuliani, G.; et al. RegCM4:model description and preliminary tests over multiple CORDEX domains. Clim. Res. 2012, 52, 7-29. [CrossRef]

32. Lazoglou, G.; Gräler, B.; Anagnostopoulou, C. Simulation of extreme temperatures using a new method: TIN-copula. Int. J. Climatol. 2019, 39, 5201-5214. [CrossRef]

33. Peucker, T.K. Some Thoughts on Optimal Mapping and Coding of Surfaces. In Geography and the Properties of Surfaces; Harvard Papers in Theoretical Geography: Cambridge, UK, 1969; pp. 1-11.

34. Peucker, T.K.; Fowler, R.J.; Little, J.J.; Mark, D.M. Digital Representation of Three-Dimensional Surfaces by Triangulated Irregular Networks (TIN); Technical Report \#10; Office of Naval Research (ONR) Geography Programs: Burnaby, BC, Canada, 1977.

35. Peucker, T.K.; Fowler, R.J.; Little, J.J.; Mark, D.M. The Triangulated Irregular Network. In Proceedings of the Digital Terrain Models (DTM) Symposium, St. Louis, MI, USA, 9-11 May 1978; pp. 516-540.

36. Delaunay, B. Sur la sphère vide. Bull. Acad. Sci. USSR VII Class. Sci. Mat. Nat. 1934, 7, 793-800.

37. Akaike, H. Information theory and an extension of the maximum likelihood principle. In Proceedings of the 2nd International Symposium on Information Theory, Tsahkadsor, Armenia, 2-8 September 1971; pp. 267-281.

38. Schwarz, G. Estimating the dimension of a model. Ann. Stat. 1978, 6, 461-464. [CrossRef]

39. Ramírez, J.; Jarvis, A. High-Resolution Statistically Downscaled Future Climate Surfaces; International Center for Tropical Agriculture (CIAT); CGIAR Research Program on Climate Change, Agriculture and Food Security (CCAFS): Cali, Colombia, 2008.

40. Jacob, D.; Bärring, L.; Christensen, O.B.; Christensen, J.H.; De Castro, M.; Deque, M.; Kjellström, E. An inter-comparison of regional climate models for Europe: Model performance in present-day climate. Clim. Chang. 2007, 81, 31-52. [CrossRef]

41. Christensen, J.H. Regional climate projections, in Climate Change 2007: The Physical Science Basis. In Contribution of Working Group I to the Fourth Assessment Report of the Intergovernmental Panel on Climate Change; Solomon, S., Ed.; Cambridge Univ. Press: Cambridge, UK, 2007.

(C) 2020 by the authors. Licensee MDPI, Basel, Switzerland. This article is an open access article distributed under the terms and conditions of the Creative Commons Attribution (CC BY) license (http://creativecommons.org/licenses/by/4.0/). 